\title{
DANGEROUS TIME: A CRITICAL QUALITATIVE INQUIRY INTO EARLY CHILDHOOD EDUCATORS' PERSPECTIVES ON PLANNING TIME IN SOUTHERN ONTARIO
}

\author{
by
}

Lisa Kathleen Johnston, BA, Ryerson University, 2014

\author{
An MRP \\ presented to Ryerson University \\ in partial fulfillment of the \\ requirements for the degree of \\ Master of Arts \\ in the Program of \\ Early Childhood Studies
}

Toronto, Ontario, Canada, 2019

(C) Lisa Kathleen Johnston 2019 


\section{AUTHOR'S DECLARATION FOR ELECTRONIC SUBMISSION OF A MRP}

I hereby declare that I am the sole author of this MRP. This is a true copy of the MRP, including any required final revisions.

I authorize Ryerson University to lend this MRP to other institutions or individuals for the purpose of scholarly research

I further authorize Ryerson University to reproduce this MRP by photocopying or by other means, in total or in part, at the request of other institutions or individuals for the purpose of scholarly research.

I understand that my MRP may be made electronically available to the public. 


\section{ABSTRACT \\ DANGEROUS TIME: A CRITICAL QUALITATIVE INQUIRY INTO EARLY CHILDHOOD EDUCATORS' PERSPECTIVES ON PLANNING TIME IN SOUTHERN ONTARIO}

CLisa Kathleen Johnston 2019

Master of Arts

Program of Early Childhood Studies, Ryerson University

This critical qualitative inquiry lifts the silenced voices of early childhood educators about their perspectives on planning time. Planning time is essential for educators to plan and document ongoing curriculum-making. Yet, not all educators are afforded this time, exacerbating poor wages and working conditions and contributing to stress, burnout and high turnover rates. Framed with feminist poststructuralism and queer time, this study situates planning time within discourses of neoliberalism and developmentalism and reconceptualizes it as a dangerous site of transformation and activism. Nine ECEs participated in a focus group discussion, and two provided written responses. The findings support educators' need for daily, ample time with their partners to plan and document curriculum along with a revision of unrealistic expectations. Moreover, this study discovers how educators are resisting oppressive power and discourses and identifies how they may further use the transformational document, How Does Learning Happen? as tool in their resistance.

Keywords: early childhood educators, planning time, transformation, resistance, neoliberalism, developmentalism 


\section{ACKNOWLEDGEMENTS}

To my incredible partner Paul Johnston for his enduring love, patience, time and support over the last year, for the many walks in the forest and for always listening.

To my supervisor Dr. Rachel Langford, for opening my horizons to the reconceptualizing ECE movement, for believing in my vision for this study and skillfully guiding me towards its realization. Thank you for all you do for early childhood educators on a grand scale and for your time and support in helping me to grow as an educator, a researcher, a writer, and an activist.

To Dr. Susan Jagger, for championing my writing, opening doors, opening my mind, supporting me in my first conference presentation and for setting the stage for an amazing year as a graduate student.

To all of the participants who generously and openly shared their time and perspectives, and for their dedication to children and families

To my graduate student colleagues for your friendship, stimulating discussions, ongoing encouragement and insights. I believe in all of you. 


\section{DEDICATION}

I dedicate this research study to all early childhood educators in Ontario who generously give their time, going above and beyond everyday to create spaces and communities where children and families belong. To the resisters and challengers of the status quo, may we find our collective voice as women to continue to resist unrealistic expectations and rise up to transform early childhood education into more democratic and livable spaces.

I also dedicate this research to Paul Johnston, my partner in the revolution. 
Table of Contents

AUTHOR'S DECLARATION FOR ELECTRONIC SUBMISSION OF A MRP ............ iii

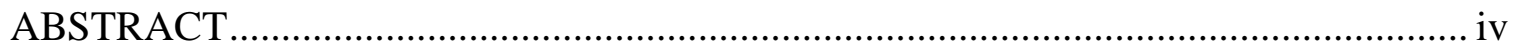

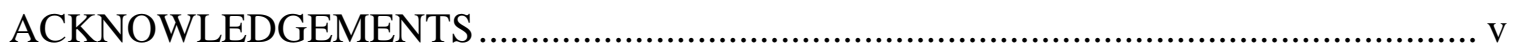

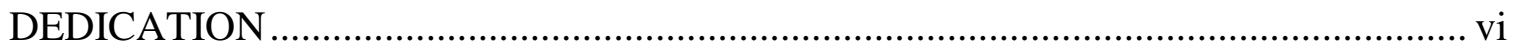

LIST OF APPENDICES ..................................................................................... ix

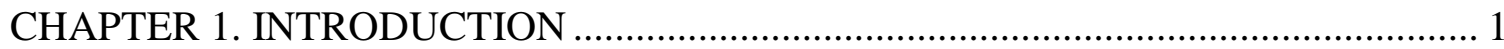

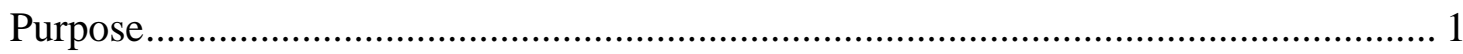

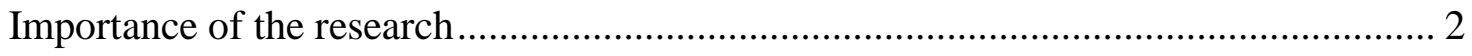

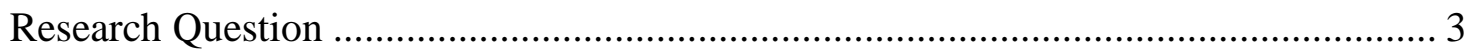

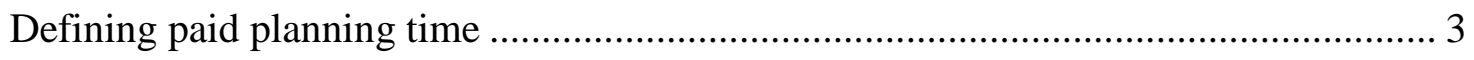

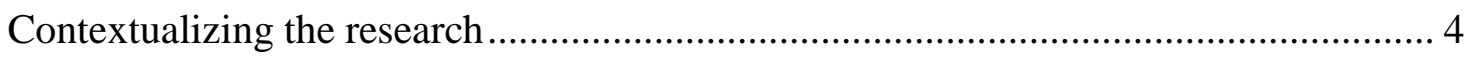

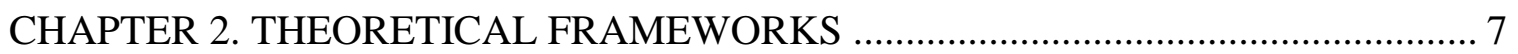

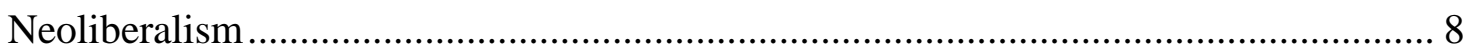

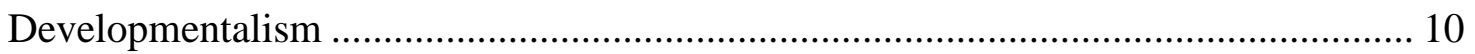

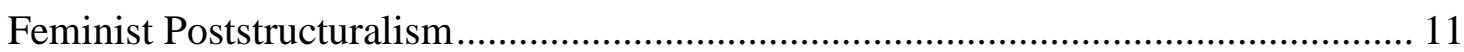

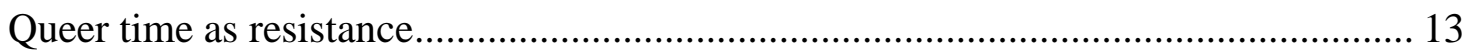

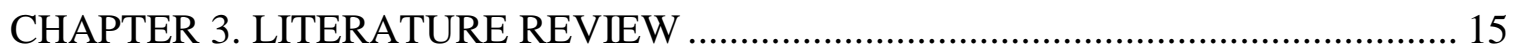

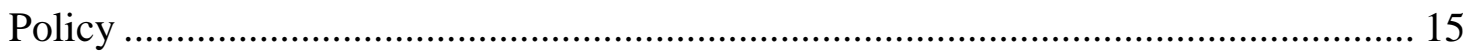

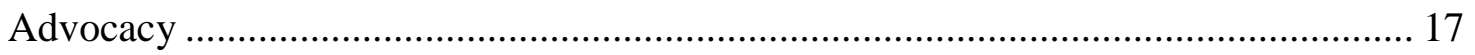

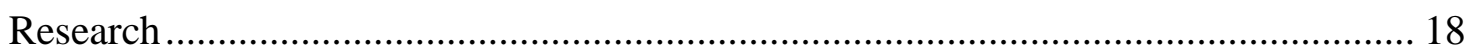

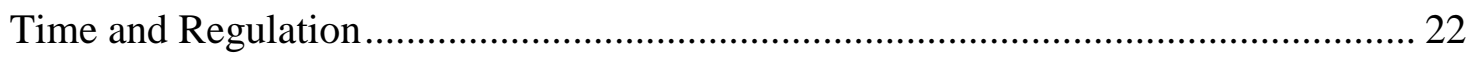

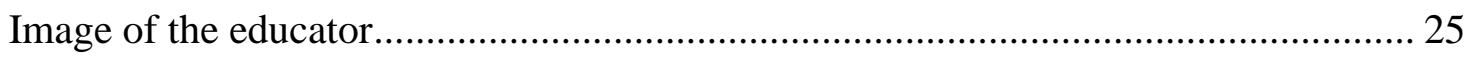

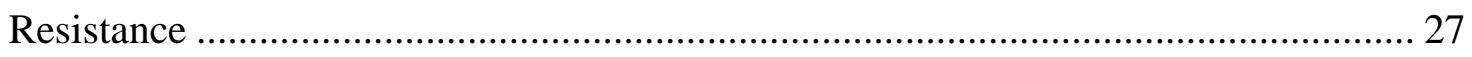

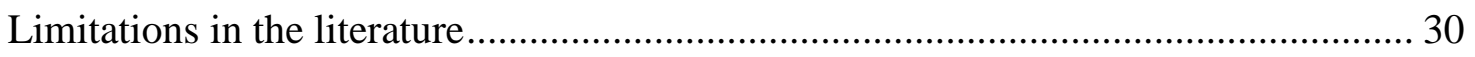

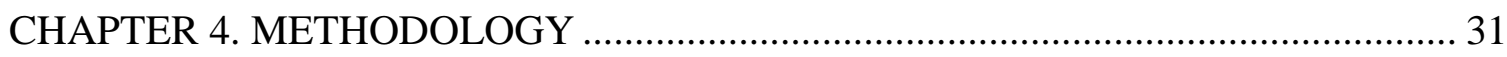

Rationale and Approach............................................................................... 31

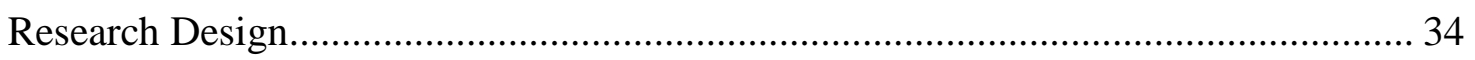

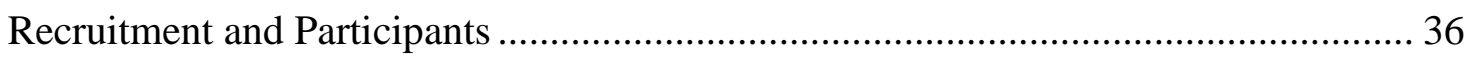

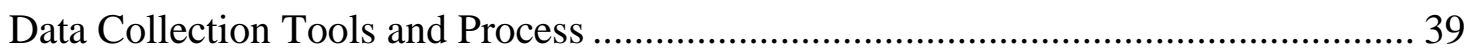

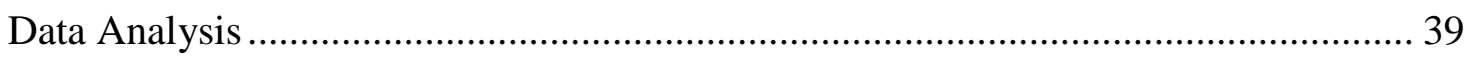

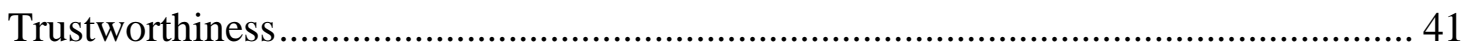

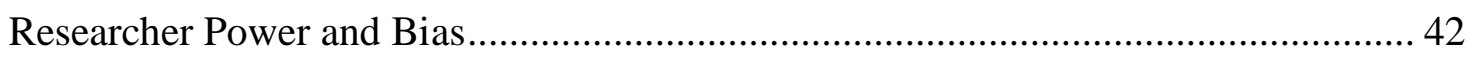

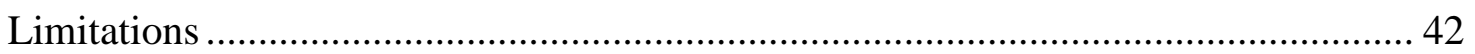




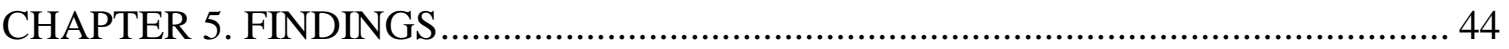

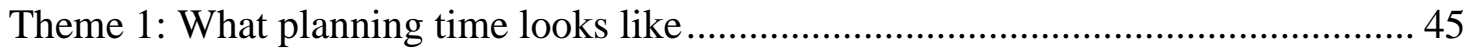

Theme 2: Expectations of educators during planning time ...................................... 50

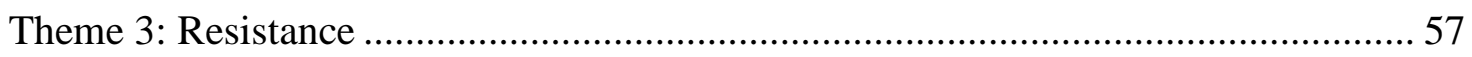

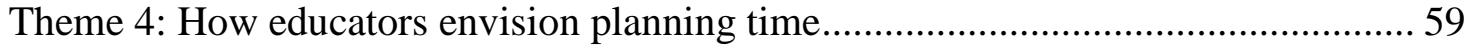

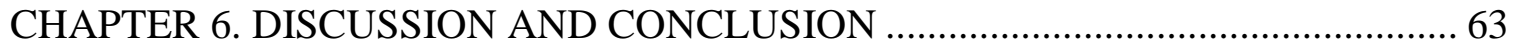

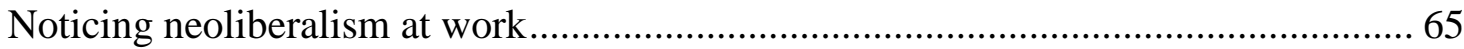

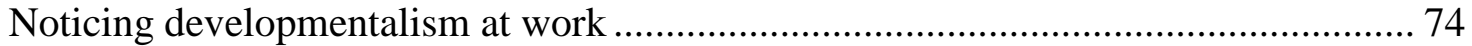

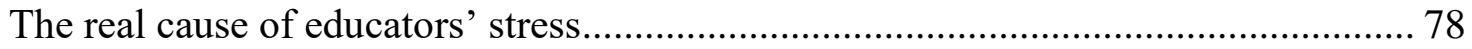

Resistance within/out neoliberalism and developmentalism .................................. 80

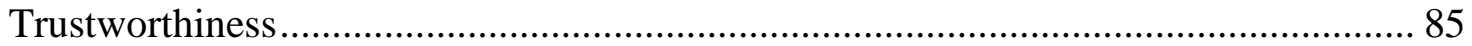

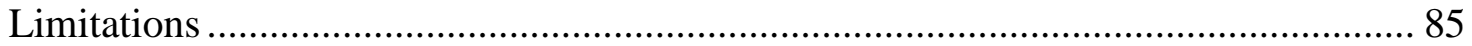

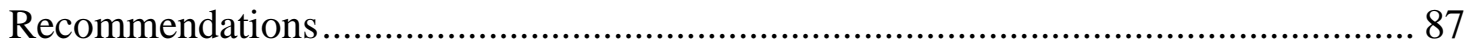

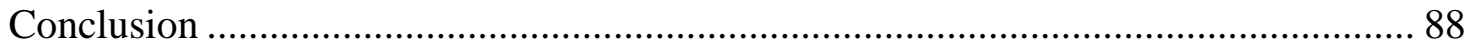

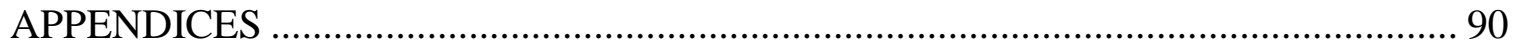

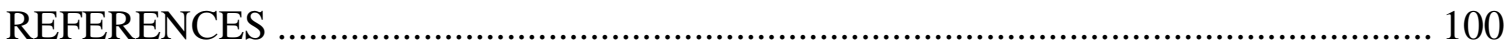




\section{LIST OF APPENDICES}

Appendix A: Interview Guide.................................................... 90

Appendix B: Recruitment Flyer.................................................. 94

Appendix C: Consent Form........................................................... 


\section{CHAPTER 1. INTRODUCTION}

Planning time for early childhood educators (ECEs) is highly contentious. Some educators have paid planning time, and some do not. For those who do get paid planning time it is questionable how much of that time they are able to use for planning, considering the increasing regulations in the early childhood sector. Planning time is often seen as a neutral time, in that all early childhood educators (ECEs) should have paid planning time and it should be used for the express purpose of planning curriculum. However, I argue that it is not a neutral time at all. It is a non-innocent, political, ethical, dangerous time. It is dangerous because not all educators are afforded it despite its inherent necessity. It is non-innocent, political and ethical because of its entanglement with certain dominant discourses that influence how planning time is taken up in early childhood education policies and practices and by the fact that the majority of ECEs who need planning time are women.

\section{Purpose}

The primary purpose of this study is to lift the voices of educators out of the confines of the staff room and the shadows of research practices into the clear light of day to better understand how they conceptualize their planning time experiences. The secondary purpose of this study is to search for lines of flight (Deleuze, Guattari \& Massumi, 1987) where planning time may be reconceptualized as a site of transformation for early childhood educators and programs. This research contributes to the scholarship about the wages and working conditions of ECEs and the stress that they experience, highlighting the importance of having paid planning time. It also contributes to reconceptualist literature that examines early childhood education and the role of the educator from poststructural and feminist perspectives (Bloch, Swadener \& Cannella, 2018; Cannella, 1997, 2018; Dahlberg, Moss \& Pence, 2006; Langford, 2007, 2010; 
Langford, Richardson, Albanese, Bezanson, Prentice \& White, 2017; MacNaughton, 2003, 2005; Moss, 2006, 2010, 2019; Osgood, 2006; Pacini-Ketchabaw, Nxumalo, Kocher, Elliot \& Sanchez, 2015).

\section{Importance of the research}

Research studies that examine the early childhood workforce are mainly quantitative (Child Care Sector Human Resources Council, 2013; Doherty, Goelman, LaGrange \& Tougas, 2000; Kipnis, Whitebook, Almaraz, Sakai, \& Austin, 2012; Phillips, Lea, Austin, \& Whitebook, 2016; Whitebook, \& Ryan, 2011). These studies rarely mention paid planning time, or, if they do, they include it in general reports on working conditions. Some qualitative studies about working conditions for ECEs have briefly captured ECE voices on the topic of paid planning time within larger discussions of working conditions (AECEO, 2016b; Boyd, 2013). However, there are no studies that have explored this issue exclusively. Thus, the voices of educators are largely missing from research. Ryan and Goffin (2008) argue that is important to include educators' voices in research that potentially informs policies which directly impact their work.

In my personal experience as an ECE working without paid planning time, I can attest to the stress it causes, how it interrupts relationships with children and instills a feeling of always being rushed, of never having enough time and of not being good enough. This experience has informed my belief that early childhood educators need paid planning time. These beliefs further inform this research project. I contend that paid planning time should be a given for every early childhood educator and program. I further contend that while having paid planning time will ameliorate wages and working conditions for educators and give educators more time to spend with children, just having the time is insufficient in order to respond to the times that we

currently live in. In order to enact a transforming society approach in early childhood education 
(MacNaughton, 2003), educators need time to think, read, theorize, question, collaborate, critically reflect and discuss together how they will respond to the unique and situated contexts in which they work. I believe that eschewing rigid measures of quality and challenging the status quo in favour of a pedagogy of care and education that addresses the ethical and political concerns of educators and sees educators as intellectuals and researchers will transform our profession and our future.

\section{Research Question}

In this study I ask, “What are ECEs' perspectives on planning time?” In asking this question, I hope to illuminate what the program planning experience is like for ECEs who have both paid and unpaid planning time from a range of contexts as well as to understand how ECEs conceptualize planning time. Knowing how ECEs experience and conceptualize planning time will allow for a further investigation into how planning time is entangled in neoliberal constructs of time and regulations that also shape the image of the educator and potentially incite resistance.

\section{Defining paid planning time}

Paid planning time for early childhood educators in the current context of this study refers to time that is consistently set aside, away from children, during working hours, for the purpose of planning a weekly curriculum or program plan. The program plan is a written document in an early childhood education program that comprises all of the activities and curriculum experiences that are planned on a weekly basis and are based on the early childhood educators' observations of children's emerging play interests and developmental skills. It is not a singular, stand-alone document, but rather a culmination of the ongoing curriculum process of observing children, documenting their learning and play, collaborating and communicating with colleagues, seeking and gathering resources, collecting and/or making materials, and 
implementing the decided upon activities and experiences. Once the program plan is complete it is posted for the week and implemented daily. Observations continue to be made as activities are implemented. Observations are then documented for the purpose of informing the next program plan and for sharing with families. Documentation of children's learning and development is collected and prepared to share with families, often using specifically designed apps, meant to make the documentation process quicker and easier and instantly shareable with families. Documentation is also added into individual children's portfolios and displayed in the classroom. Clearly this is a vast and endless process that is currently fundamental to the work of ECEs, which is why advocates argue that educators need consistent, paid time in order to do this essential work. However, this study goes further putting this process of curriculum-making into question by situating it within critiques of dominant structures and discourses.

\section{Contextualizing the research}

ECEs have long advocated for paid planning time to improve their working conditions (Doherty et al., 2000). While planning for and documenting children's learning is mandated by law (Ontario Ministry of Education, 2014a) and the early learning framework in Ontario, Early Learning for Every Child Today or ELECT, clearly states that ECEs be given time to plan (Best Start Expert Panel on Early Learning, 2007; Ontario Ministry of Education, 2014b), employers are not legally required to give ECEs paid planning time. In Ontario's most recent pedagogical document, How Does Learning Happen? (HDLH) (Ontario Ministry of Education, 2014c) ECEs are positioned as researchers, who are critically reflective and engaged in collaborative inquiry. This image of the educator requires that there is time to engage meaningfully in these ways, yet this is not the reality for many ECEs (AECEO, 2016a). In fact, the current standardization and regulation of practice seems to position educators more as technicians rather than researchers 
(Moss, 2006). While there are some employers that do support educators with paid time to plan for and document children's learning, many do not (Child Care Human Resources Sector Council, 2013; Doherty et al., 2000). A lack of paid planning time is most often identified as an aspect of the poor working conditions of ECEs (Doherty et al., 2000), but when ECEs are working on their lunch breaks or at home, then it is also a matter of wages (AECEO, 2016b; Boyd, 2013).

Planning time is enmeshed in layers of intersecting and overlapping tensions and concerns. Professionalization of the early childhood sector in Ontario, since 2007, has brought increased regulations and requirements for ECEs that continually add to ECEs' workloads. Advocates and activists, internationally and provincially call on governments to enact policies that provide professional pay and decent work, including paid planning time, for educators (AECEO, 2017; OECD, 2017; Urban, Vandenbroeck, Laere, Lazzari \& Peeters, 2012). Furthermore, a lack of paid planning time for educators, as an indicator of poor working conditions, contributes to stress (Boyd, 2013; Curbow, Spratt, Ungaretti, McDonnell, \& Breckler, 2000; Faulkner, Gerstenblatt, Lee, Vallejo, \& Travis, 2016; Wagner, Forer, Cepeda, Goelman, Maggi, D’Angiulli \& Grunau, 2013), depression and burnout (AECEO, 2017; Blöchliger \& Bauer, 2018; Phillips, Lea, Austin, and Whitebook, 2016; Roberts, Gallagher, Daro, Iruka, \& Sarver, 2017) which eventually leads to higher staff turnover rates (Totenhagen, Hawkins, Casper, Bosch, Hawkey \& Borden, 2016). Advocates and researchers argue that the steady increase of demands without an increase of supports is unsustainable and dangerous for the health and well-being of early childhood educators.

As an early childhood educator, I have lived in these tensions, becoming increasingly frustrated, dissatisfied and dejected about my work. I was spending more time working to fulfill 
expectations that were meant to im/prove quality and less time with children, which, in my opinion, undermined an already tenuous definition of quality. I often described the daily schedule as a high-speed train that didn't stop, and I was holding on for dear life. The train didn't seem to have a destination except to just keep going. Perhaps its destination was simply the status quo. I wanted to get off this train and do things differently, to slow down, but I didn't know how to do it without a great amount of risk. I longed deeply for a different way. The reconceptualizing ECE movement (Bloch, Swadener \& Cannella, 2018) offered me a way to understand the context that I was living in and a way out, to slow down, to resist and to think about early childhood education in a way that is responsive not only to children but to the times and contexts that we, as educators, and as women are living in.

In the following chapters, I lay out the theoretical frameworks chosen to guide this study and through which the data will be analyzed. In the literature review, I locate planning time in policy, advocacy and research scholarship and then examine how planning time is viewed from feminist and reconceptualist perspectives. In the methodology chapter, I describe the design and the process of the study. Finally, I present the analyzed findings from the focus group discussion and written responses of the eleven participants, followed by a discussion of the findings and future research directions. 


\section{CHAPTER 2. THEORETICAL FRAMEWORKS}

The question of planning time for early childhood educators lies within two embedded narratives. It is first found in the narrative of wages and working conditions, wherein early childhood educators, as women, make very low wages and endure poor working conditions that cause stress and burnout. Improving these conditions has been the work of advocates and educators for decades. Recently this work has resulted in the professionalization of the early childhood sector in Ontario. However, professionalization has not materialized in significantly improved wages or working conditions at all, but rather in increased regulations and expectations for educators. This prompts an investigation into the bigger narratives in which wages and working conditions and thereby planning time are situated, namely, neoliberalism and developmentalism.

In the late 1970's and into the 1980's, theorists in anthropology, psychology and sociology began to critique the dominant psychology-based discourses of child development, as well as the systems of neoliberalism that had taken hold in education, giving rise to a growing movement known as the reconceptualizing ECE movement (Bloch, Swadener, \& Cannella, 2014). Taking up post developmental and postfoundational theories such as feminism, queer theory, poststructuralism, postcolonial and posthuman theories, the reconceptualizing ECE movement explored alternative ways to think about, question, and practice early childhood education. This research study is guided by feminist poststructuralism and queer time as theoretical and conceptual frameworks. Feminist poststructuralism is useful in examining how discourse, power, subjectivity and resistance are present in the perspectives of female educators about planning time. Also, as time is a central notion of this study, queer time as a theory, offers a critical perspective from which to challenge and unsettle dominant narratives and normative 
constructions of time. It provides alternative ways to think about, resist and reorder time in a way that is responsive to educators in local contexts. I offer here descriptions of neoliberalism and developmentalism as the dominant systems and discourses in which early childhood education is embedded and grounded and which this study seeks to further question and disrupt, followed by a discussion of feminist poststructuralism and queer time and how I will use them in this study.

\section{Neoliberalism}

As support for the expansion of the welfare state began to decline in North America around the 1970's, a return to economic liberalism was championed and re-emerged in the form of neoliberalism (Davies \& Bansel, 2007). Neoliberalism's presence is often invisible, but its effects can be seen in education and the environment. Moss (2019) describes neoliberalism as the big story of how lives in the English-speaking parts of the world are governed by economic markets. Early childhood education operates in a market-based system that caters to parents as consumers. Markets are influenced by the choices of consumers thereby creating competition. Competition then works to ensure "quality" and offer a high return on investment. Moss (2019) identifies quality and high returns as two of the big narratives of neoliberalism in early childhood education. In order to be competitive in the markets and offer high returns, time and practice are standardized so that they become more efficient and easily managed.

Neoliberalism values individuality and consumerism. It has shifted the narrative away from the ideals of the welfare state, in which it was the government's responsibility to look after its citizens, to one in which each individual is their own entrepreneur, and is morally obliged to do the best for their own family (Davies \& Bansel, 2007). In this way, all social issues have been reshaped as economic issues. Neoliberalism has taken a particular hold in education as a site to reproduce citizens as future taxpayers, consumers and entrepreneurs. Further, neoliberalism is 
critiqued as a masculinized and patriarchal system that uses various forms of regulation and surveillance to control women and racialized groups who are identified as having 'feminine' traits such as dependency (Osgood, 2006). Women, as teachers and early childhood educators, are particularly subject to these forms of control and regulation, while at the same time they carry out the mechanisms in education to reproduce future neoliberal subjects (Cannella, 1997). Osgood (2006) argues that masculine neoliberal ideals of individuality and the entrepreneur silences the feminine characteristics of care and emotionality in early childhood education because they cannot be measured or counted and therefore have little value in the market. Care work, which is generally seen as women's work, and work that takes place privately, not publicly, is relegated to a lower status below public education. This keeps the work of caring for young children in a market-based system resulting in perpetually low wages and poor working conditions for educators (Halfon \&Langford, 2015).

Taking an even wider view of the effects of neoliberalism in education, Moss (2010) questions how neoliberalism and capitalist greed, predicated on modernist ideals of scientific progress, has led to the continuous and unsustainable cycle of capitalist production and consumption. Some call the time that we are living in now the Anthropocene, which is marked by extreme environmental destruction and the climate crisis (Haraway, 2016). Moss (2010) urges that we cannot continue as we are and argues that alternative narratives need to be cultivated that create an education for social justice, democracy and survival. More than what neoliberalism is however, as Vintimilla (2014) argues, is what neoliberalism does in early childhood education and how it creates subjects and practices through its pervasive discourses. 


\section{Developmentalism}

Developmentalism is another grand narrative in early childhood education about how children develop from birth to adulthood. Based in developmental psychology and attributed to a small group of Euro-Western male psychologists namely, Jean Piaget and Erik Erikson, developmental theories have been unquestioningly taken up in early childhood education in most English-speaking countries like the Canada, the U.S, England, Australia and New Zealand. In the United States and Canada, developmentally appropriate practice (Bredekamp \& Copple, 1997) is taught in most pre-service early childhood education programs as the foundation of early childhood education theory and practice. Developmentalism in early childhood education has been critiqued for its normalization of development to white middle class standards, its linear focus on the development of children as becoming adults, ignoring who they are as beings in the moment and for its pathologizing of children who do not fit into universalized norms of development (Bernhard, 2002; Burman, 1994; Walkerdine, 1988). Others also point out that developmentalism does not adequately address racism and colonialism in education and thereby continues to perpetuate it (Escayg, Berman \& Royer, 2017).

Moss (2015) argues that the problem with developmentalism is that it has set itself up as the only narrative of childhood in early childhood education, silencing and "othering" those that do not fit into this narrative. It is also deeply entangled in neoliberalism in that it is focused on reproducing what Foucault would call "docile bodies" (Foucault, 1979), or, in this context, subjects that are conditioned for functioning within the neoliberal market of consumption and production without questioning it. It is against this that feminists and reconceptualists in early childhood education take an ethical and political stand and seek a new path and purpose for early childhood education and educators (Moss, 2010). 


\section{Feminist Poststructuralism}

I have chosen to use St. Pierre's (2000) overview of feminist poststructuralism in education as my primary source for discussing the theoretical framework for this study as it offers tools and concepts to challenge and disrupt the structures of neoliberalism and developmentalism. As her works draws on Foucault, I will also use Foucault $(1979,1980)$ directly as well as Cannella (1997) who provides an early yet still very relevant feminist deconstruction of early childhood education. St. Pierre (2000) discusses how "[f]eminists in education increasingly use poststructuralism to trouble both discursive and material structures that limit the ways we think about our work" (p. 477). Poststructural theories question the dominant discourses perpetuated by modernist thinking, coming out of the Enlightenment era, that claim certain truths about the way things are, for example developmentalism in early childhood education or narratives that perpetuate the superiority of men over women. Referring to Foucault, St. Pierre (2000) offers the following understanding of discourse.

Foucault's theory of discourse illustrates how language gathers itself together according to socially constructed rules and regularities that allow certain statements to be made and not others. [...] Even more important, the rules of discourse allow certain people to be subjects of statements and others to be objects. Who gets to speak? Who is spoken? Discourse can never be just linguistic since it organizes a way of thinking into a way of acting in the world. (p. 485)

Foucault (1980) also refers to discourses as "regimes of truth", which, regardless whether or not they are true, become the accepted way of functioning (p. 131).

Power is embedded in discourse and structures (Osgood, 2006; St. Pierre, 2000). Foucault $(1979,1980)$ points out "disciplinary power" which, he notes, is present everywhere and is internalized by individuals so that they regulate themselves. He describes how "normalizing technologies" of control categorize individuals and compare them to universal norms, producing "docile bodies" that do not challenge the status quo. Osgood (2006) recognizes this power as the 
regulatory gaze, in her analysis of the discourse of professionalism in early childhood education, which consists of the rules that govern how educators do their jobs and stories about who is a good and/or professional educator. Modernist discourses construct the educator, as a subject of discourse, as a fixed, bounded and knowable subject (St. Pierre, 2000). Feminist poststructuralism, however, rejects the notion of a fixed and knowable subject and posits that women, who are born into patriarchal ideologies, take up certain discourses that construct their subjectivity, while at the same time being subjected to discourses that oppress them (St. Pierre, 2000). And they may take up or reject different discourses at different times. St. Pierre (2000) explains that for feminist poststructuralists, examining discourse means questioning patriarchy (power) to find out where it is located and how it works to subjectify and oppress women, and not just women, indeed everyone. Once the discourse of patriarchy can be found and named, then, she argues, it can be resisted (St. Pierre, 2000, p.486). Osgood (2006) also notes that,

It can be considered a liberating theory when power is seen as embedded in discourse and the concept of a 'fixed self' is denunciated; for feminists post-structural theory highlights the complexity of gender relations and demonstrates a fresh way of understanding discourse and hence power relations, enabling an understanding of how power within a discourse is constituted and providing possibilities for creating new discourses through which the individual can become reconstituted (p. 10)

Foucault $(1979,1980)$ contends that where there is power, there is resistance. Cannella (2018) points to ethical substance and ethical work as ways that educators and researchers may reconstruct their subjectivity into an ethical self: by acknowledging that within power there is the possibility to resist, that knowledge is only partial and that there are other ways to know and be known, and that their orientations toward social justice will inform how they act ethically with others. St. Pierre (2000) points out that the goal of resistance is not a complete liberation from power, but an ongoing daily exercising of resistance within power relations. 
In this study I will use the feminist poststructural concepts of discourse, power, resistance and subjectivity to examine how structures regulate and control the practice of early childhood educators; how the dominant neoliberal and developmental discourses in early childhood education are internalized and shape the image of the early childhood educator as a professional who should have planning time; and how educators currently resist and may be empowered to engage in further acts of resistance and transformation.

\section{Queer time as resistance}

Emerging from queer theory during the time of the AIDS crisis in America, queer time disrupts the heteronormative expectations of the time of marriage, reproduction, family life and inheritance (Halberstam, 2005, Silin, 2018). Silin (2018) eloquently states, "[i]mpelled by a sense of imminent mortality, queer theorists valorized the present as the moment in which the past and future can be fully understood and realized" (p.60). This rejection of reproductive and traditional temporalities led to a postmodern re-ordering of time that is non-linear, and that opens up possibilities for new narratives and new ways of thinking and doing time (Halberstam, 2005; Silin, 2108). Halberstam (2005) identifies queer time as a useful framework for challenging the normativity and respectability of Western ideals of temporality. Silin (2018) relates the goals of queer time, that focused on the "complexity of lived lives", with those of reconceptualists in early childhood education who also valued complexity and questioned the linear and futureoriented logics of time in developmental theories (p. 61).

As developmental theories of childhood are embedded within and maintain neoliberalism, queer time can be used to question and disrupt neoliberal logics of time in early childhood education as well. Using queer time will be useful in unsettling clock time and "rigid production schedules" (Wien, 1996, p. 377) that operate in the name of quality, accountability 
and progress (toward what?). It is also interesting to think of queer time alongside poststructural feminist notions of power, resistance and subjectivity, and to ponder queer time in the face of an imminent climate crisis.

A final note and acknowledgement about the human centered approach to this study. I recognize that a human centered (feminist poststructuralist) approach is limiting in some ways. I also recognize and that by placing humans always at the centre of research and discourse can be problematic in light of larger issues that humans and all species on this planet face. I have alluded to posthuman theories somewhat in my discussion of neoliberalism and ultimately I contend that planning time as a time to think, read, question, theorize, and discuss has enormous potential to open doors for educators to begin to critically reflect not just on what is happening with the children in their program but also on the systems that oppress and regulate them and society. It is my hope that planning time would be a generative time that would begin to shift paradigms and build alternative narratives that broaden to encompass the more than human world in the creation of more democratic and livable spaces (MacNaughton, 2003; Moss, 2019). 


\section{CHAPTER 3. LITERATURE REVIEW}

This literature review weaves together the many contexts for understanding the complexities and potentialities of planning time for early childhood educators (ECEs). It is set up in two parts. First, it situates planning time amid the landscape of policy, advocacy and research. Then from feminist and reconceptualist perspectives, it explores how planning time is shaped by neoliberal constructions of time and regulations, how these constraints then shape the image of the female early childhood educator and finally how educators resist and are called to resist.

\section{Policy}

In Ontario's curriculum framework documents, planning time is both explicitly and implicitly noted to be a requirement for educators. The ELECT document (Best Start Expert Panel on Early Learning, 2007) now replaced by its updated version, Excerpts from ELECT (Ontario Ministry of Education, 2014b), sets out six foundational principles that, among others, recognize the importance of a planned curriculum and educators as knowledgeable, responsive, reflective practitioners who "require a working environment that provides time for program planning, observation and documentation, opportunities for professional development and regular conversations with families" (p. 20). ELECT is firmly based in universal developmental theories of childhood and includes a tool, known as the Continuum of Development, that charts children's development in five domains with corresponding skills from birth to school age.

Educators are generally required to refer to the ELECT document when planning and documenting curriculum and are expected to make specific connections to the domains and skills directly on the program plan and in their documentation. 
Said to build on ELECT, How Does Learning Happen? Ontario's Pedagogy for the Early Years, (HDLH) (Ontario Ministry of Education, 2014c) provides a different pedagogical direction for educators, opening up a new landscape of curriculum-making for children guided by four foundational goals for children's well-being, belonging, engagement, and expression. $H D L H$ also envisions the early childhood educator as a researcher and co-learner with children, engaging in critical reflection and collaborative inquiry (pg.13). While ELECT's Continuum of Development is grounded in theories of developmental psychology and developmentally appropriate practice (Bredekamp \& Copple, 1997), HDLH strives to move away from early childhood education's reliance solely on developmental theories and is instead inspired by the Reggio Emilia approach to incorporate other theories of childhood and children, and ways of thinking and doing early childhood education.

Reggio Emilia is a city in Italy whose approach to education, grounded in its own "distinctive and innovative set of philosophical and pedagogical assumptions" that value children as capable and competent in their own learning processes and within the context of their larger community, has influenced early childhood education around the world (Edwards, Gandini \& Forman, 2012, p. 6). Reggio Emilia inspired educators support children's intellectual growth through the use of symbolic representation and also by encouraging children to explore and express themselves in a multitude of ways, which are referred to as the Hundred Languages of Children (Edwards, Gandini \& Forman, 2012, p. 7). Inspired by Reggio Emilia, HDLH "invites educators to consider a more complex view of children and the contexts in which they learn and make sense of the world around them" recognizing that, "[t]his thinking may require, for some, a shift in mindsets and habits. It may prompt a rethinking of theories and practices" (Ontario Ministry of Education, 2014c, p. 17). 
Curriculum planning and planning time then are situated somewhere between ELECT and $H L D H$; two documents that are not quite aligned with each other but that are meant to work together to guide Ontario ECEs in curriculum making. In relation to planning time, ELECT clearly states that educators need time to plan and $H D L H$ positions educators to engage in critical reflection and collaborative inquiry, which logically requires time (Best Start Expert Panel on Early Learning, 2007, p. 20). Yet, there is no official legislation or policy requiring early childhood education program employers to provide paid planning time to ECEs.

Planning and planning time are monitored at local levels. Some municipalities have instituted or updated their quality assurance measures which they use to regularly inspect childcare centres. In the City of Toronto, where this study mainly takes place, all childcare centres that have subsidized childcare spaces, must also adhere to the minimum requirements for quality set out by the city in the Assessment for Quality Improvement ( $A Q I$ ) rating scale (City of Toronto, 2019), formerly known as the Metro Operating Criteria. Childcare programs are rated on a scale from 1 to 5, where a 1or 2 "does not meet expectations", a 3 "meets expectations" and 4 or 5 "exceeds expectations". The $A Q I$ sets specific requirements for program plans and planning time. Childcare programs must post a program plan to meet expectations for quality and centres that provide paid time away from children for educators to complete program plans are recognized as exceeding expectations for quality requirements.

\section{Advocacy}

Educators, researchers and advocates have long been calling for paid planning time. In one international study, Urban, Vandenbroeck, Laere, Lazzari, \& Peeters (2012) strongly and specifically advocate for "paid 'non-contact' time, continuous professional development, support for practitioner research and critically reflective practice" as part of the "structural conditions" 
that contribute to quality early childhood systems (p. 510). Provincially, the Association of Early Childhood Educators Ontario (AECEO) and the Ontario Coalition for Better Childcare (OCBCC) have been actively working to improve wages and working conditions for early childhood educators (See www.aeceo.ca and www.childcareontario.org). The AECEO, in addition to running ongoing advocacy campaigns with their local communities of practice to call for government implementation of decent work (including paid planning time) and professional pay for early childhood educators (AECEO, n.d.), published an article in support of the newly launched How Does Learning Happen? pedagogy outlining structural conditions needed for educators to fully activate the new pedagogical approach (AECEO, 2016a). After adequate compensation they recommended "sufficient time" was required "to reflect, plan and document with others" (AECEO, 2016a, p. 8). The AECEO's Decent Work Task Force also submitted workforce strategy recommendations to the Ontario Ministry of Education in 2017 based on province wide consultations with early childhood educators. Among its recommendations, the Task Force called for paid planning time for early childhood educators, childcare workers and ECEs in Full Day Kindergarten (FDK) programs (AECEO, Decent Work Task Force, 2017). In fact, in 2018 the former Liberal government adopted many of their recommendations and was poised, albeit at the last minute, to implement free preschool and a wage grid for ECEs before they were toppled by a new Conservative government that quickly dissolved those plans.

\section{Research}

It is difficult to know for certain how many ECEs are supported with paid planning time in Ontario. In 1999, the You Bet I Care study surveyed 4,699 childcare centres in ten provinces and two territories in Canada and found that over half of the educators working in municipal and non-profit centres reported that they were given paid planning time, while just under half of the 
educators working in for-profit setting reported being given paid planning time. Insufficient planning time was identified in the category, "Nature of Work", as the fourth most frequently cited "negative aspect of working in childcare" (Doherty, Lero, Goelman, LaGrange \& Tougas, 2000, p. 87). It was also linked to job dissatisfaction. Moreover, paid planning time was among the top five recommendations by educators for improving working conditions (Doherty et al., 2000). The follow up study, You Bet We Still Care, showed a nearly 10 percent drop in the number of ECEs in 2013 who reported receiving paid planning time than in the previous study, indicating that working conditions were worsening (Child Care Sector Human Resources Council, 2013). This is the last time this data on childcare was collected in Canada.

Now planning time, in other national reports such as The Early Childhood Education Report or ECER, must be inferred in factors related to workforce stability, such as being employed in the public sector, being unionized, and having "competent management and access to resources that support the work" (Atkinson Centre, 2017, pg. 13). Working in the public sector and in unionized workplaces affords educators the power of having a collective voice in securing improved working conditions including paid planning time. This was also noted in Phillips et al.'s (2016) research where ECEs working in the Department of Defense in the United States were afforded paid planning time and in the You Bet I Care study (Doherty et al., 2000), where educators working in municipal and non-profit centres were more likely to have paid planning time.

The move of the early childhood education sector to the Ontario Ministry of Education in Ontario in 2010 was hoped to bring about some recognition of ECEs as professionals as well as an improvement in wages and working conditions for ECEs in childcare and Full Day Kindergarten (FDK) programs. While ECEs in FDK programs did see an increase in wages 
(though they are laid off in the summer and forced to access employment insurance), those in the childcare sector did not. According to some recent studies about the new FDK teaching model in Ontario, kindergarten teachers are given planning time with other kindergarten teachers, but teachers and their ECE partners are not given any formal planning time together or their planning time is very limited (Janmohamed, McCuaig, Akbari, Gananathan, \& Jenkins, 2014; Underwood, Santo, Valeo, \& Langford, 2016). Underwood et al. (2016) found that both kindergarten teachers and ECEs recognized that planning time together was extremely important for the partnership to work and this was ultimately one of the recommendations coming out of the study.

Despite the two national studies mentioned above (Childcare Human Resources Sector Council, 2013; Doherty et al., 2000), paid planning time is rarely addressed in research and usually only in the context of working conditions for ECEs. As a factor of poor working conditions (Child Care Sector Human Resources Council, 2013; Doherty et al., 2000; Kipnis, Whitebook, Almaraz, Sakai, \& Austin, 2012; Phillips, Lea, Austin, \& Whitebook, 2016; Whitebook, \& Ryan, 2011), a lack of paid planning time seriously impacts the health and wellbeing of early childhood educators, their interactions with children, and quality in early childhood education programs. In the literature, a lack of paid planning time is linked to job dissatisfaction (Doherty et al., 2000) and is identified by early childhood workers as a factor that negatively affects their work (OECD, 2015, 2017; Atkinson Centre, 2017; Doherty et al., 2000; Totenhagen, Hawkins, Casper, Bosch, Hawkey, \& Borden, 2016; Whitebook \& Ryan, 2011; Kipnis, Whitebook, Almaraz, Sakai, \& Austin, 2012).

Work stress, related to poor working conditions, is well documented in the early childhood profession (Boyd, 2013; Curbow, Spratt, Ungaretti, McDonnell, \& Breckler, 2000; Faulkner, Gerstenblatt, Lee, Vallejo, \& Travis, 2016; Wagner, Forer, Cepeda, Goelman, Maggi, 
D'Angiulli \& Grunau, 2013) and is also related to job dissatisfaction as well as feelings of exhaustion and frustration. In the study by Wagner et al. (2013), findings indicated that feelings of exhaustion and frustration were related to greater perceived stress in early childhood educators. Burnout symptoms and depression were found to be associated with workload and increased job demands with fewer resources to support the work required (AECEO Decent Work Task Force, 2017; Blöchliger \& Bauer, 2018; Roberts, Gallagher, Daro, Iruka, \& Sarver, 2017). Phillips, Lea, Austin, \& Whitebook (2016) cite a number of studies that show a correlation between teacher stress and depression and negative interactions with children.

Where stress, burnout, and depression are common, workforce retention becomes a serious concern that can have a negative impact on the quality of early childhood education services for children and families (Doherty et al., 2000; Halfon, \& Langford, 2015; OECD, 2006, 2015, 2017; Totenhagen et al., 2016; Urban et al., 2012). In a review of the literature focusing on the retention of workers in the early childhood sector, Totenhagen et al. (2016) identified studies that showed turnover rates were highly correlated to low job satisfaction and high burnout. They also highlighted studies that found an increase in organizational support (like paid planning time) related to a decrease in workers' intentions to quit their job. In order to improve workforce retention these studies and reports recommend investing in higher wages and better working conditions (including paid planning time) for early childhood educators (Doherty et al., 2000; OECD, 2006, 2015, 2017; Totenhagen et al., 2016; Urban et al., 2012). Making the point that early childhood educators are a gendered and marginalized workforce whose wages and working conditions are not helped by being early childhood education being in a market system, Halfon and Langford (2015) go even further to recommend that early childhood education be moved out of the market system into a publicly funded system to address these issues. 
This recommendation by Halfon and Langford (2015) prompts me to critically interrogate how the issue of planning time, as a matter of educators' working conditions, is shaped by its location within the neoliberal market system and by discourses that shape the image of early childhood educator. To accomplish this, I draw on feminist and reconceptualist scholars to consider the following questions. How has the growth neoliberalism continued to affect the wages and working conditions of a gendered and marginalized workforce? And how has it shaped the image of the early childhood educator? Is moving early childhood the education to a publicly funded system enough to address these issues or is something more needed to genuinely transform early childhood education?

\section{Time and Regulation}

Wages and working conditions, including a lack of paid planning time for educators, are currently determined by the way that neoliberalism constructs time and regulations to manage early childhood education in a consumer market. Clock time currently rules early childhood settings (Kummen, 2010; Pacini-Ketchabaw, 2012; Rose \& Whitty, 2010; Wien, 1996; Wien \& Kirby-Smith, 1998). Based on a scientific, Newtonian construction of time (Adam 1994), clock time, which is disconnected from seasons and the rhythms and patterns of nature, universalizes, controls and forces all living things to adapt and adjust to its constructs (Adam 1994, 2006).

Time controlled by the clock can be measured, traded and commodified leading to a speeding up of time in an effort to increase profit by doing and producing more within less time (Adam 1994, 2006; Tronto, 2003). Rose and Whitty (2010) contend that

By the $21^{\text {st }}$ century, in many parts of the world, the clock in its multiple analog and digital forms calls people to work, to work efficiently, to work faster and to work more productively. It calls us to standardize work with time, with our bodies and with others' bodies - sometimes propelling us at speeds that feel beyond our control (p. 260). 
Early childhood educators, who are predominately women, live in the tension between this decontextualized, sped up market time and their entanglement with the rhythms of care and patterns of nature in their work with young children. Tronto (2003) refers to this as the time/space compression and highlights the gendered nature of time, noting that care responsibilities, which generally fall to women, do not easily fit into time that is controlled for efficiency and production. She states, "[t]ime assumes a different aspect from the standpoint of care. Time spent caring is not about mastery and control but about maintenance and nurturance" (p. 123). Adam (2006) also recognizes that women's time “does not register on the radar of commodified time" (p. 124) and discusses the difference between time controlled and time lived, as in relationships of care and of the ebb and flow of human life. Both Adam (1994) and Tronto (2003) insist that time must factor into a response to contemporary contexts, urging a questioning of time in social and political contexts and offering encouragement that those involved in care work have the power to rethink and reorder time. Dahlberg, Moss and Pence (2006) also encourage educators to struggle against the "tyranny of time governance":

We live in a world that is increasingly time-governed, driven by new technologies and demands for increasing productivity. We are saturated with information. We demand and expect instant answers and quick fixes. We do not make time for other things, not least reflection, dialogue, critical thinking, working the tensions between theory and practice. Perhaps one answer to "What can we do?" is to say the we will struggle against the tyranny of time governance; we will risk crises by choosing to work with complexity, finding ways to think critically and searching for new questions; by doing so we will open up the possibility of new understandings and practices. (p.17)

The standardization and commodification of time inevitably leads to a standardization and commodification of practice through regulation. Osgood (2006) discusses how neoliberal policy reforms in Britain (similar to the Ontario context), intended to increase the professionalization of early childhood educators, have brought with them an increased regulation of the workforce through objective measures of quality. These measures act as "disciplinary" and 
"normalizing technologies" (Foucault, 1978,1979). In Ontario, these technologies are recognized as the regulations set out in the Child Care and Early Years Act (Ontario Ministry of Education, 2014a) as well as municipal quality assurance measures like the City of Toronto's AQI (City of Toronto, 2019). Osgood (2006) aptly refers to this increase in regulations as the regulatory gaze and argues that the intensification of educators' workloads shifts their focus toward meeting the expectations for professionalism and quality leaving them too busy to think about anything else (p. 6).

Osgood (2006) critiques the masculinized nature of neoliberalism within in the discourse of professionalism and shows how early childhood educators, who are predominately women, are subjected to regulations meant to ensure high standards of quality but which are incommensurable with an ethics of care (Langford, Richardson, Albanese, Bezanson, Prentice \& White, 2017; Osgood, 2006). Neoliberalism values individuality and the entrepreneur and relies on disciplinary technologies (Foucault, 1979) to regulate individual performance within the system, while the feminine characteristics of care work cannot be easily measured or regulated and therefore have "little exchange value" in the market (Tronto, 2013; Osgood, 2006, p. 9). Osgood (2006) examines how the image of the educator is structurally constructed through the imposition and internalization of masculinist, neoliberal regulations and socially constructed through the discourse of professionalism which silences the discourse of an ethics of care. Just as St. Pierre (2000) contends that once power is named it can be resisted, Osgood (2006) argues that through a deconstruction of these discourses, educators can play a role in creating a counter discourse of who they are that reinstates an ethics of care. 


\section{Image of the educator}

Planning time is deeply entangled in the image of the educator as a professional. As professionals, educators should have paid time to plan their programs and document children's learning. Yet, the location of early childhood education in a market system means that educator salaries are mostly paid for by families, who cannot sustain an increase in fees to cover the costs of giving educators time off the floor to plan and document. Further, within the market system, neoliberal regulation of early childhood education coupled with the dominance of developmentalism, constructs the educator as a technician and creates a discourse of the good educator, which educators are compelled to live up to. These images usurp the image of the educator as a true professional. Moss (2006) describes the technician as one who applies "a defined set of technologies through a regulated process to produce pre-specified and measurable outcomes" (p. 35). This view is also inextricably linked to the predetermined outcomes in developmental psychology. Just as educators are subjected to measurable outcomes of performance, so too do they apply similar outcomes to children as prescribed by developmental psychology (Moss, 2006). Cannella (1997) traces the history of teacher training as an applied science and as "non-intellectual" (p. 145) because women were deemed too emotional and not objective. She connects the technical approach to early childhood education with the "medical views of women as those who would apply the information given them about children by physicians" (p. 145). In the context of developmental psychology then, educators merely apply the information given them by developmental psychologists.

Cannella (1997) noted how neoliberal regulations not only work to construct the image of the good educator externally but are also internalized so that educators regulate themselves.

The discourses and actions associated with professional institutions and practice have generated disciplinary and regulatory powers over teachers (who are mostly women) and 
children. Standards have been created through which individuals judge and limit themselves, through which they construct a desire to be "good," "normal" or both (p. 138).

Langford's (2007) study of discourses that create the image of the good educator further reveals the distinct connection between this image and the way that educators in preservice education take up developmental discourses and approaches to early childhood education. Smith and Campbell (2018) describe how educators spend "hours of their own time and work" to create portfolios of individual children that "comprised developmental observations, digitally recorded and individualized 'learning stories,' photos, and samples of artwork” (p. 316). They describe how these portfolios were inspected each year and were evidence of their status as "good" educators. The time spent on maintaining this status is not paid and therefore is not valued. In Ontario, the ELECT document with its focus on developmental outcomes, contributes to this image of the good educator as well as the image of educator as technician. Using specialized knowledge of child outcomes, educators can claim to know a child and create documentation that proves this knowledge.

How Does Learning Happen? however, repositions the early childhood educator as a researcher. It envisions educators being involved in critical reflection and collaborative inquiry. This is a move away from the educator as the expert in ELECT toward an educator who questions. Moss (2006) describes the educator as researcher as "a reflective and dialogic practitioner, whose work depends on relationships and the ability to listen and engage in dialogue" (p. 35). The problem with this image of the educator in a neoliberal system is that it is "unmanageable and unquantifiable, and hence impossible for the state to regulate" (Osgood, 2006, p. 9). 


\section{Resistance}

Feminist and reconceptualist scholars call for educators to resist the devaluing and normalizing technologies of neoliberalism (Cannella, 1997, 2018; Langford, 2010;

MacNaughton, 2003, 2005; St. Pierre, 2000; Tronto, 2003), the regulatory gaze (Osgood, 2006), and the limitations of developmental theories (Cannella, 1997) in order to create more democratic spaces (Dahlberg \& Moss, 2005) and bring about a transformation in early childhood education for educators as well as children, families and society (MacNaughton, 2003). This involves ongoing critical reflection, reflexivity and questioning of the status quo. MacNaughton (2003) describes current iterations of early childhood education as being either conforming, reforming or transforming. A conforming to society approach to early childhood education is based in developmentalism and believes that education should be guided by standardized social goals set out and monitored by governments (p.121). A reforming society approach is also based in developmentalism and values a child-centred pedagogy that seeks to create an individualized, independent self -regulating child (p. 155). Our current child centered early childhood education system can be located in the reforming society approach.

In contrast, MacNaughton (2003) proposes a transforming society approach to early childhood education, which recognizes that education is political and works with children and families to create more democratic and livable worlds. It is oriented toward social justice and takes an ethical and political stance. It takes up critical theories that challenge structures and systems of oppression and gives children the skills and knowledge to "confront injustice and resist oppressive ways of becoming" (p. 183). In order to activate a transforming society approach to early childhood education, MacNaughton $(2003,2005)$ insists that educators have time to engage in critical reflection together. This need to have time to engage in discussion as a 
collective is echoed by others who call for a change in the way early childhood education programs are enacted (Iorio, Parnell, Quintero, \& Hamm, 2018; Smith \& Campbell, 2018).

However, time must also be accompanied by a disposition to question and challenge the status quo. Smith and Campbell's (2018) work offers a roadmap of resistance for educators, a source of wayfinding and an orientation to finding lines of flight (Deleuze, Guattari \& Massumi, 1987) within regulations that are open to interpretation. Their regulatory context, in Australia is akin to Ontario's, including a curriculum framework that is similar to $H D L H$. Smith and Campbell (2018) also describe similar experiences of working within increasing regulations due to professionalization. However, they identify borders of resistance and compliance (p. 316), spaces and times within the regulations which can be reinterpreted based on their ethical and political dispositions. For example, they choose to use a single journal to document the daily curriculum-making of the children and educators in the class instead of creating individual portfolios for children. This gives them more time to spend with children and opens up space to address issues of class, race and sexism that are silenced by other forms of documentation, like portfolios. In doing this, they anticipate and indeed receive low marks on their quality inspection. But they are not deterred. Instead, they respond by collectively analyzing how they experience receiving low marks.

Ontario's pedagogical document How Does Learning Happen? takes up many of the ideas in a transforming society approach. I see it as a tool of resistance. It positions educators as researchers, as critically reflective and encourages collaboration and collectivity in its focus on relationships. It infers that educators have time to engage in these practices that are not solely based in the production and consumption of documentation. It also invites educators to question and challenge the status quo and alludes to the need for a shift in mindsets and a reconsideration 
of theories and practices beyond developmental theories. However, this aspect of the document remains largely invisible to most educators, and until recently, myself included.

Resistance to neoliberalism and developmentalism is not just important for educators and children, it is also important for the survival of the planet (Moss, 2010). Feminist posthumanist theorists like Donna Haraway, (2016) who discuss the age of the Anthropocene, in which we are now living, and the damage that human activity and capitalist greed have done to the planet, go even further in urging a critical re-evaluation of humanist points of view toward multi-species and more than human perspectives. Reconceptualist scholars have taken up Haraway's theories in early childhood education and are rethinking how early childhood education can respond to the urgent climate crises facing the planet (Pacini-Ketchabaw \& Kummen, 2016; PaciniKetchabaw, Nxumalo, Kocher, Elliot \& Sanchez, 2015; Taylor, 2018). Moss (2010) echoes these ideas in questioning the purposes of early childhood education and early childhood educators. He argues that the neoliberal cycle of production and consumption that is reproduced in early childhood education is unsustainable. Thus, he challenges educators to reconsider early childhood education as an education for survival, social justice and democracy.

The problem with all of these calls to resistance is that they require time and a disposition toward critical pedagogy in order to be activated. Neoliberal constructions of time orient educators' time toward producing measurable outcomes, like a program plan and various forms of documentation, while critical pedagogy requires a time to read, think, theorize, question, and discuss. With time for educators to critically reflect together, $H D L H$ can become a tool of resistance that opens up space, lines of flight (Deleuze, Guattari \& Massumi, 1987), for educators to question and challenge the status quo. 


\section{Limitations in the literature}

Planning time and educators' voices are both largely silenced in the literature. This is problematic because it silences educators' voices on their experiences and insight into their work and essentially excluding their input into policy recommendations. Ryan and Goffin (2008) point out the missing voices of educators in most research and argue that it is critical for those central to early childhood education to be included. Likewise, the reconceptualist literature is not always clear about how educators "find" time to, not only plan, but to think, read discuss and theorize other kinds of time and ways to resist neoliberal regimes of truth and time.

MacNaughton (2005) argues that capturing early childhood educators' perspectives [on planning time] and telling their stories is a political act. This study is intended to be a site of activism (Wolff, 2013) that will potentially support advocacy campaigns fighting for decent work and organizations that are positioned to make policy recommendations to the Ontario government. I also hope that this study will engage educators in a new discussion about how their planning time, practice and their own subjectivity are entangled in and shaped by neoliberalism and, also, how these can be questioned, disrupted and rethought and resisted. 


\section{CHAPTER 4. METHODOLOGY}

\section{Rationale and Approach}

The voices of early childhood educators are largely missing from research that is about them (Ryan \& Goffin, 2008). As the ones who are most affected by policy and legislation, ECEs' voices must be heard and included in research that informs policy (Ryan \& Goffin, 2008). Quantitative research on the poor working conditions of ECEs includes a lack of paid planning time for educators, though it is often hidden among other statistics (Child Care Sector Human Resources Council, 2013; Doherty et al., 2000; Kipnis, Whitebook, Almaraz, Sakai, \& Austin, 2012; Phillips, Lea, Austin, \& Whitebook, 2016; Whitebook, \& Ryan, 2011), while only a small number of qualitative studies capture ECEs' voices about this issue (AECEO, 2016b; Boyd, 2013). I did not find any studies that focus exclusively on early childhood educators' experiences of or perspectives on planning time. This overlooked and undervalued time is further discounted by not being emphasized in research, which could be a reflection of the invisibility of educators both in research and in general (Langford, 2010; Ryan \& Goffin, 2008). I argue that planning time, though seemingly insignificant, has enormous potential, not only to improve wages and working conditions for ECEs but also for transforming programs into more democratic and livable spaces and times (MacNaughton, 2003; Moss, 2019). In order to capture the complexity (Denzin, 2017) and richness of ECEs perspectives on their experiences with paid and unpaid planning time, and to situate this research as a site of activism (Wolff, 2013; Cannella, 2018), I chose to use a critical qualitative inquiry approach.

According to Cannella (2018) and Cannella, Perez and Pasque (2016), critical qualitative inquiry is a multidisciplinary form of interpretive qualitative research that is oriented toward social justice and activism. Critical qualitative inquiry has emerged from modern rights 
movements and postmodern thinking that is critical of how power operates in intersecting ways. It brings together qualitative research approaches with critical thinking to disrupt taken for granted truths about the way things are and to examine how power is used to privilege and oppress but also to resist (Cannella, 2018; Cannella, Perez \& Pasque, 2016; Denzin, 2017). This approach to methodology is in line with feminist and reconceptualist thinking that interrogates how narratives of developmentalism, and neoliberal market economics dominate the sector and how these can also be unsettled and resisted (Burman, 1994; Dahlberg, Moss \& Pence, 2006).

In challenging and unsettling dominant discourses, a critical qualitative inquiry approach takes an ethical and political stand within the research. MacNaughton (2005) agrees that "identifying the stories (of individuals or societies) that are silenced or marginalized and then sharing them is a political act” (p. 4). Denzin (2017) posits that the role of the qualitative researcher is not to simply interpret the world but to change it. While proponents of critical qualitative inquiry do not provide a standard model of how to conduct research from this orientation, they do offer tenets that are necessary to activate in order to consider the research critical (Cannella, 2018; Denzin, 2017). While there are different variations of how these are communicated, I like the way that Cannella and Lincoln (2011) posit them. They suggest that the researcher should: "expose the diversity of realities; engage directly with webs of oppression; reposition problems and decisions toward social justice; and join in solidarity to create new ways of functioning" (Cannella \& Lincoln as cited in Cannella, 2018, p. 345). They also recommend using non-traditional theories in critiquing and repositioning the issues raised in the research within and towards social justice and caution researchers to have humility in the work to avoid re-inscribing oppression through activism. Ultimately, as Denzin (2017) suggests, inquiry can be 
used with activism to help people and affect policy change by raising voices of critique to be heard by policy makers.

These tenets are useful in my research as I seek to foreground the voices of early childhood educators, a predominately female workforce (Child Care Sector Human Resources Council, 2013), about an issue that is rarely addressed and is not given the focus it necessitates. In gathering the rich, complex perspectives and realities of how ECEs experience and conceptualize their planning time, and then repositioning their stories through a feminist poststructural and a queer time lens, I engaged indirectly in "webs of oppression" (Cannella \& Lincoln as cited in Cannella, 2018, p. 345 ). I anticipated that sites of resistance would emerge as possibilities for new ways of functioning in early childhood education. Finally, as an ECE who has experienced working without paid planning time, I am embedded in this community not only as a researcher but also as a participant. I acknowledge my bias in this work as well as my position of power as the researcher. I take seriously my responsibility to present the research honestly and reflexively. To this end, I used journaling as a research tool (Mukherji \& Albon, 2010) to record my thoughts and feelings during the research process and to help me critically reflect on and analyze the decisions and choices I made during the data collection and analysis processes. I also referred to my theoretical frameworks to continuously question my methods and motives and to guide me in this study.

In this study I asked the question, "What are the perspectives of ECEs on planning time?" This information illuminated what planning time is like for ECEs who have paid and/or unpaid planning time from a range of contexts. Through a feminist, reconceptualist and queer time lens, this study further explored how ECEs' planning time is understood in the context of neoliberal constructions of time and regulation which create discourses that shape the image of the educator 
and also invites educators to resist. This study has been reviewed and approved by Ryerson University’s Research Ethics Board.

\section{Research Design}

As this study seeks to understand the perspectives of ECEs with paid and unpaid planning time, who are often unheard and ignored in their pleas for more time, I chose to use a focus group design as an ideal way for that discussion to occur among the participants. This design also contributes to more authenticity and trustworthiness in the data analysis as the participants' own understandings and voices are foregrounded (Leavy, 2017). Farquhar and Tesar (2016) point to a number of studies that identify the potential for focus groups to lead participants towards more critical reflection and activism. This element of focus groups is well suited to the purpose of this study in that it seeks to understand how ECEs see potential for change and improvement in their working conditions as well as how they may reconceptualize planning time as a place to think, theorize, discuss and challenge the status quo.

Kitzinger (1994) identifies two other important aspects of focus group interactions: complementary and argumentative interactions. Complementary interactions refer to the shared understandings and shared culture of the participants. Despite the different working contexts of each of the participants in this study, they discussed a shared culture and understanding of their experiences with planning time. Argumentative interactions relate to the differences among participants in how participants understand or misunderstand each other. The participants in this study did differ in their experiences and at times questioned the practices of other participants.

These types of interactions helped the focus group serve as, what Farquhar and Tesar (2016) call, a "temporal ecosystem" (p.261). It provided an opportunity for the participants to feel connected and heard and contributed to a conceptualization and reconceptualization of 
planning time. Educators rarely have enough time to meet all of the requirements expected of them on a daily basis including planning their programs, so it is even rarer for educators to have an opportunity to talk about their experiences and challenges, especially as the sector professionalizes and more demands are placed upon them. This focus group, as a "temporal ecosystem" was a model of what I contest that planning time could be; a space and time to think, discuss, question and theorize, not to necessarily produce something, like a program plan or documentation, but to simply engage in thoughtful discussion.

During the focus group, I used semi-structured interview questions (see Appendix A) to elicit the voices of ECEs in discovering how they experience and conceptualize planning time. These questions offered flexibility for participants to engage in open-ended discussion and to raise issues that they wanted to discuss as well. (Leavy, 2017; Farquhar and Tesar, 2016). I drafted my own questions for this study with insight and input from my supervisor. The questions started with "what" or "how" or "please describe" to ensure an open-ended design which centered around the main research question (Creswell, 2014). I used a mix of questions to encourage participants to reconstruct as well as reflect on their experiences (Seidman, 2013). A study by Smith and Campbell (2018), that explored a similar topic, identified questions that the researchers and educators were asking themselves which they later revisited and analyzed against other documents and texts. For example, their questions asked, "Why am I not coping with the increased demands?" "Why am I spending more time working?" "Why am I spending less time with children and families?” (p. 314). Their questions were helpful in guiding the creation of some of the questions for this study.

As there are limitations to conducting focus groups, I first acknowledged my power as a researcher and situated myself also as an ECE with the experience of not having paid planning 
time (Farquhar and Tesar, 2016). To ensure that everyone was engaged and included in the conversation, I intervened at points among some of the more dominant voices (Farquhar \& Tesar, 2016). Also, during the focus group the participants engaged in such rich discussion amongst each other, time ran out before I was able to ask all of the questions that I had prepared. The participants did agree to stay an extra half hour to answer one more question. Four of the focus group participants sent in supplemental written responses to the questions that were not asked.

\section{Recruitment and Participants}

I used purposeful sampling to ensure that I targeted populations that had a concentrated number of potential participants (Leavy, 2017). I recruited participants through two email lists as well as select Facebook groups. First, I sought permission to email recruitment information to the membership lists of the Association of Early Childhood Educators Ontario (AECEO) and the Ontario Coalition for Better Childcare (OCBCC). These are large organizations that exclusively serve early childhood educators and programs. The email included a recruitment letter (Appendix B) outlining the purpose of the study, the date and time of the focus group and the participant criteria requested for the study. It also included an informed consent letter (Appendix C) outlining details about the study, risks and benefits, the participant's rights to confidentiality and a reminder that their participation is strictly voluntary. These organizations also posted the recruitment flyer on their respective Facebook pages. Second, I sought permission to post the recruitment information for the research study on two other Facebook groups: Early Childhood Educators of Ontario and Continuous Professional Learning. I chose these groups as I also subscribe to them and know that they are active groups where the members are engaged in posting and commenting on others' posts. Following ethics protocols about posting on social 
media sites, I created a separate Facebook account that was used exclusively to post the recruitment flyers on these Facebook groups.

Responses to my post on one of the Facebook groups, caused me to reconsider and redesign the selection criteria for the recruitment of participants part way through the recruitment phase. Originally, I had asked for participants who were Registered ECEs (RECEs) only, working full time in licensed centre-based childcare centres in Toronto and working with infants, toddlers or preschool aged children. I refer to ECEs here as RECEs due to the fact that in 2007, early childhood education in Ontario became a regulated profession requiring all ECEs to be registered with the College of ECE in order to hold the title of RECE and to practice as an ECE (College of Early Childhood Educators, 2019). The potential participants also had to have been working for at least five years. My rationale for choosing these criteria were first of all due to the location of the focus group being in Toronto, and second that RECEs working full time with those age groups would most have the most responsibility for the maintenance of their program and would also likely experience the most stress by not having planning time. I also wanted participants who had been working for some time and were most likely committed to the profession (Holochwost, DeMott, Buell, Yannetta, \& Amsden, 2009). However, I received a lot of questions about why the selection criteria excluded others in a variety of working contexts who also do not have planning time. This caused me to critically reflect on the parameters for my selection criteria.

As I reflected on my selection criteria and on the purpose of critical qualitative inquiry to engage marginalized and silenced voices, I realized that my original selection criteria were actually a reflection of my own experience as an ECE and did not take into account the complexity of educator roles in the sector. Furthermore, as both critical qualitative inquiry and 
reconceptualizing ECE theories value opening up complexity and interconnectedness (Denzin, 2017), and complexifying rather than simplifying (Dahlberg \& Moss, 2018), I chose to redesign my selection criteria to include the complexity of participant experiences and voices. The resulting selection criteria for the study (approved by Ryerson's REB) centered on anyone working full time or part time as an ECE or childcare worker in any licensed childcare centre or full day kindergarten program for a minimum of two years.

Once I broadened the selection criteria for participants, I was able to recruit enough participants for the focus group. Eleven people participated in the study altogether. Nine attended the focus group and two submitted written responses in lieu of attending. I purposefully did not collect demographic information about age, gender, or race, as I wanted to focus on the complexity of the participants' working contexts. As a predominately female workforce (Childcare Human Resources Sector Council, 2013), ECEs are already considered marginalized, and their voices on this topic have been largely silenced. As such, they meet the criteria for a critical qualitative inquiry. In general terms, the focus group participants were predominantly women and roughly half were white. The demographic information that I did collect pertained exclusively to the working contexts of the participants.

The following description of the participants captures the complexity of their working contexts. All the participants were Registered Early Childhood Educators (RECEs), and two also had experience as supervisors. The length of time they had worked as RECEs ranged from 4 years to almost 30 years. Of all the participants, six reported that they worked in unionized settings. This included one participant with two positions worked in a unionized setting in one role and in a non-unionized setting in another. Two participants worked as ECEs in Full Day Kindergarten (FDK) programs within two different school boards. All participants, except one, 
worked in non-profit centres. Surprisingly, out of the total eleven participants, eight reported that they received paid planning time, including one who described their paid planning time as inconsistent. The participants chose their own pseudonyms. They are Molly, DD, DJ, Gina, Frida, Kiana-Monae, Phoebe, Miley, Trisha, DSSD, and Espey D.

\section{Data Collection Tools and Process}

The focus group took place in a classroom on Ryerson University's campus and was scheduled to last 90 minutes. The location was chosen as it was a convenient space to host the session. I provided consent forms and information letters at the focus group session and informed the participants about the purpose study and reminded them of voluntary nature of their participation before they signed consent forms. I also informed them that the focus group discussion would be audio recorded and that they had the option not to participate if they felt uncomfortable. I informed them that I and my supervisor would be the only people with access to the recording and that I would be the one to personally transcribe it. Audio recording the focus group session supported my ability to engage in active listening as the researcher, although I did make some notes and used initials to track who was speaking to aid in transcribing the audio recording later. After the focus group discussion, I informed the participants that I would make arrangements to follow up with those who may wish to review the research findings in order provide feedback and to ensure that their voices, experiences and meanings have been accurately transcribed. The focus ended with some closing comments, and I thanked the participants for their generous participation.

\section{Data Analysis}

The audio recording of the focus group was transcribed verbatim immediately after the session. This was done to preserve the complete record of the discussion (Leavy, 2017). I spent 
time thinking about the data as it was being transcribed in order to get a strong sense of the unfolding story of the data. This immersion into the data helped to develop some initial ideas about the nature of the data and then to begin to identify some emerging ways to categorize and find themes in the data (Leavy, 2017).

I chose to analyze the data inductively using a process of coding. The coding process took part in three phases, open coding, axial coding and selective coding (Neuman \& Robson, 2011). During the open coding phase of the analysis, I read through the data twice (both the transcript of the focus group discussion and the written responses) and looked for critical terms and word. I assigned initial codes to words and phrases that were significant. Guided by the theoretical frameworks of queer time and poststructural feminism, I also identified discourse, power, subjectivity and resistance in the data. During the axial coding phase, I looked for connections among the initial codes and grouped codes together to create major themes. Finally, during the selective coding phase, I reviewed the axial codes and initial codes and selected the most illustrative examples of the major themes to include in the findings (Neuman \& Robson, 2011).

I also engaged in analytical memo writing during the coding phases (Neuman \& Robson, 2011). This involved writing notes about my thoughts and ideas for each coded theme. This created a connection between the data and how it fit within the theoretical frameworks I chose to use in the study. This was also important to ensure that I continued to examine my bias during the analysis phase of the study (Leavy, 2017). Memo writing also documented and provided detailed insight into the data analysis process, the choices I made about which categories to use and how the themes emerged from the categories. This further contributed to the interpretation and trustworthiness of the data (Leavy, 2017). 


\section{Trustworthiness}

This study seeks to understand the topic in its relational, partial and provisional context (Moss, 2019). Unlike quantitative research, which focuses on the knowability and generalizability of certain concepts being studied, qualitative research does not claim to produce results that are generalizable, nor does it claim to fully know the topic being studied (Mukherji and Albon, 2010; Neuman \& Robson, 2011). Similarly, feminist poststructuralism contests the knowability of a subject or topic, positing that knowledge is always partial and contextual (St. Pierre, 2000). Furthermore, critical qualitative inquiry is not as concerned about the generalizability of the research as it is about engaging with marginalized voices, interrogating power and orienting the research toward social justice and activism (Cannella, 2018; Cannella, Perez \& Pasque, 2016; Denzin, 2017).

While qualitative research does not follow the same rules for validity and reliability as quantitative research, there are ways to ensure that qualitative research meets standards for rigor and trustworthiness (Hatch \& Coleman-King, 2015) including credibility, transferability, dependability and confirmability (Lincoln and Guba, as cited in Hatch \& Coleman-King, 2015). To ensure credibility, I engaged in member checking. Participants were given the opportunity to review the transcript and provide feedback on whether I had accurately portrayed their voices as well as adding or correcting any information. I have kept detailed notes on the research process to establish a thick description of the study. This was done to contribute to the transferability of the research, which is the degree to which the findings may be applied to other contexts. My supervisor has acted as the external auditor of the data to ensure dependability of the research, and my notes and transparent record-keeping, including notes on reflexivity, will act as an audit trail to answer the question of confirmability. Furthermore, analyzing data from different 
theoretical perspectives also ensures its trustworthiness (Leavy, 2017). Richardson and St. Pierre (2005) offer the poststructural metaphor of the crystal, arguing that the truth cannot fully been known from a single point but that it looks different depending on the angle from which it is viewed. From this perspective, I have analyzed the data using more than one theoretical lens, (i.e. feminist poststructuralism and queer time).

\section{Researcher Power and Bias}

My past professional experience as an ECE without paid planning time influenced my perspective throughout this research study. This was the case, as I have already identified, in the selection criteria and recruitment process. This bias particularly influenced how I analyzed the data in that I was surprised to find that the majority of the participants actually had paid planning time. Furthermore, my interest in and disposition toward questioning and disrupting the status quo also affected my bias in this study. However, this disposition is consistent with my methodology which, being grounded in critical qualitative inquiry, demands that the researcher take an ethical and political stand in the research. Following Mukherji \& Albon's (2010) suggestion, I used journaling to address issues of bias and power in the research process and to position myself as an instrument of the research in the study. Journaling helped me notice my reactions and responses to the data as I conducted the analysis and supported my commitment to being aware of my biases and making them transparent.

\section{Limitations}

Due to the unpredictable nature of focus group discussions, I was unable to ask all of the questions that I had originally planned in the time allotted. I was also unable to ask any probing questions. Some of the unanswered questions were provided as written responses after the focus group. Being able to ask all of the questions as well as asking probing questions might have 
revealed more information about the participants' perspectives. While the focus group design worked well to encourage rich discussion among the participants, perhaps fewer participants would have allowed for more questions to address all the questions.

In a qualitative study, the results are not meant to be generalizable, so this study is not meant to describe the greater population of early childhood educators. Also, my sample of participants is limited to Toronto and the Greater Toronto Area, with one participant in the Niagara region. Hence the results are not representative of the experiences of all ECEs in different regions and municipalities in Ontario. A larger scale study is needed make broader statements about ECEs experiences of and perspectives on planning time in Ontario.

In conclusion, this is a small-scale qualitative study that is meant to foreground the perspectives of some ECEs on planning time. It is important to hear from educators directly about their experiences as their voices are missing from research. It is also important because this is a topic that has not been the focus of any research. By using a critical quality inquiry approach, my aim is to centre the voices of educators and to question how neoliberalism, developmentalism, discourse, power, subjectivity and resistance play a role in their experiences in order to present this research as a possible site for future activism. 


\section{CHAPTER 5. FINDINGS}

The purpose of this study is to explore early childhood educators' (ECEs') perspectives on planning time. Planning time refers to the time that educators use to plan their program as well as to document children's learning. The contention is that educators need paid time away from children during the workday to engage in planning and documenting, instead of trying to do this work during the time they are with children or on their own time. In keeping with the first tenet of critical qualitative inquiry, to engage with marginalized voices, I present the findings of this study by foregrounding the voices of the ECE participants. Eleven Registered ECEs participated in this study from a range of contexts that provide educators with various configurations of planning time. This was intentional in order to exemplify the complexity of the ECE workforce and increase the credibility of the findings. The themes that emerge from the findings are not only consistent with the literature about wages and working conditions of ECEs and their experiences with stress, but they also provide greater detail and depth of understanding of the complex issue of providing paid planning time for educators, that has heretofore been unknown. The findings reveal what educators want from planning time and what paid planning time means to them.

The first theme that emerged from the data analysis focuses on the complexity of what planning time looks like. This includes descriptions of the various configurations of planning time, ways that planning time is contextual, and the fact that there is never enough time to plan. The second theme that emerged documents what is expected of educators during planning time. It reveals that educators have altogether too much to do. It highlights the expectations for documentation along with its required quotas as well as expectations to go above and beyond minimum requirements. It further reveals these expectations are a cause of educators' stress and 
exposes how the use of technology, to mitigate the problems of increased expectations, brings with it a new set of challenges. The third theme that emerged focuses on how educators are resisting by taking ethical and political stands to say "no" to some of the expectations. Finally, the fourth theme that emerged focuses on how educators envision planning time; what planning time means to educators and what they want. The results are messy and entangled. For example, some educators have more than one job and have different experiences with planning time in each position. The responses are grouped into themes but there is overlap and nuance within their responses that have been left in to demonstrate the complexity of the topic. Through this analysis of the rich focus group discussion and written responses, the participants in this study illuminate and document the realities of planning time, giving credence to the high stress levels of ECEs and offering ways to counter the stress through systems resistance and change.

\section{Theme 1: What planning time looks like}

This theme highlights the complexity of the participants' contexts of having paid or unpaid planning time, how they plan their programs during this time, what other factors affect their planning time and reveals that there is never enough time.

\section{Complex configurations: Unpaid planning time.}

Only 4 of the 11 participants identified as either not having paid planning time or having very little. The descriptions of their experiences with unpaid planning time are consistent with what the literature has captured about educators planning on their own time or during the children's sleep time. DSSD states “I did program planning in my spare time, at work, before or after my day, at meetings, at lunch, at home. Lots of unpaid paperwork!" DD who worked for four years in both private and non-profit childcare states,

They don't pay us for the planning time. One year I work as a supervisor. I was the one who was handling everything so, they never paid for the planning time, it's unpaid. 
Sometimes they say you can take it home and bring back next day or next week if it's my turn to make program plan.

Espey D describes her experiences in three different jobs in the past eight years, staying only four years each at her first two positions and less than a year at her last position. She is now taking time off to go back to school. Her following description captures the complexity of some of the different configurations of planning time:

The first place I worked at we had paid planning time. We had set times every week. Each room received an hour per classroom on a certain day (So if you had 3 teachers, you had 20 mins each). The second, we did not have planning time, but we had documentation time. This was dependent on the shift we were working but would be given to us in hour increments per staff. Available to use was a staff room, and a "gym" (which wasn't ever used as a gym, it was used for training purposes or small grouping). It would often occur that neither of these options were accessible and most people went off site to grab a coffee or run errands and completed documentation time on their own time. Planning time would occur during sleep room or on our own personal time. In terms of setting out the materials - it usually fell on the opening staff who would come in 30-60 minutes in advance to set up the classroom. The third was paid planning time. Each staff was given a half hour per week to bring materials into their room on a certain day/time of the week. The actual writing down of the plan was done during sleep room.

Kiana-Monae describes having 5 minutes of paid planning time in the morning and 10 minutes at the end of the day in one full day kindergarten classroom and 20 minutes in the morning and none at the end of the day in another. She describes how her planning takes place while she is with the children saying,

Everything is done when the children are playing. So, at the beginning there was the struggle. I'd try to make observations but now the children will come up to me as I'm planning and preparing to let me know to take a picture, just 'cause I am not engaged at all, because I'm trying to prepare.

\section{Complex configurations: Paid planning time}

As most of the participants in this study have some form of paid planning time, their stories reveal what is not known about how paid planning time is experienced in the sector. It is difficult to know how this compares to the rest of the province as this data has not been collected 
since 2013 (Childcare Human Resources Sector Council, 2013). The participants' discussion uncovers that paid planning time was inconsistent across the various working contexts represented by the participants, and even within individual programs. Planning time is affected by the specific contexts of programs, the time of year, and whether the educators are able to plan with their room partner or not. Interestingly, many of the participants with paid planning time still need to work on their own time to meet increased expectations. Gina, Frida and Molly all have one hour of paid planning time per week. Gina's planning time is together with her team. She says, "We do team teaching, so we feed off each other. We do our program and we help each other finish each other's program when we can." Frida and Molly both do their planning individually. Frida also notes that her planning time is not always consistent saying,

I have been working for the same place for the 20 years. The planning has never been consistent. It's always been inconsistent. We can spend months without any planning and then suddenly we need to pick it up again. We used to support each other. I work in the toddler room and so infants and toddlers, we used to support each other, and preschool and kindergarten, when we had kindergarten. But that also was broken down for some reason. So now it's been consistent for the past few months that they hire someone and come and relieve us.

Frida describes how planning is done individually. She states,

So, the planning is still very individual. It's not with my colleague. So, we still do in the room as much as we have the time, the dialogue that needs to be happening when we're planning, to have a quality plan, which is not the best. So, we take turns, one week my colleague plans and another week I write the plan, and we just verbalize the rest.

Molly technically gets one hour per week, but it is split up between work and home. She is paid

for a half hour at work and a half hour at home. She explains,

For the past I guess, 8 years, 9 years, we only had the thirty minutes of programming time that was paid for outside of our work time. This year I was like, this is not happening. I wanted more. Like a half hour at work. So, they have someone coming in and covering each staff for a half hour on the floor. We did ask, you know, can we bump that half hour at home time within the work time, and was told yes but then we would lose out on something else. So, it was like, no, it's not worth it. So, we do half hour at work, half hour at home, technically speaking but our programming time, it's never enough. 
Trisha, who works in a full day kindergarten classroom as well and gets paid planning time every day but not with her teaching partner says,

We have half an hour of planning time in the morning before the work starts, before the kids come. So, my classroom starts at 8:45, but I start at 8:15. In between I have some duty too from 8:35 to 8:45. But because we are part of a school board, our roles are different. Your partner has different preparation times, so you are never together to plan. And then on a bigger spectrum, you are just like flying. You are talking on the fly. It would be beneficial if both the partners get some amount of time together.

Miley, Phoebe and DJ have the most paid planning time and speak positively about their experiences. Phoebe gets a half hour everyday off the floor with her room partner. She describes how having time together everyday is effective and gives her and her partner time to do other tasks as well. She says,

We feel that we work better off each other. It goes a lot faster that way and then, usually we have like Thursday, Friday, we just do other activities that we plan. Cut things out if we have to. You know, get things prepared for the following week that we might need.

DJ has two positions. He is a supervisor in a drop-in program for half of the day and also works as a part time RECE in an after-school program. He has roughly an hour of paid planning time in each setting. He says, "I am so lucky to be in both centres that have an hour planning time for me." Miley also describes herself as being "spoiled" because she has a half hour everyday as well as set up time. She and her room partner have autonomy about how they use their planning time. They plan individually and share the time over the week. She explains,

Our centre gives us the autonomy to decide how we use it [paid planning time]. So, in our classroom, I would use Monday to Wednesday if I'm on the early shift and she would use Thursday, Friday on the late shift so she can plan for next week, and then vice versa depending on what shift we're on. But the other classrooms do it differently.

It wasn't always this way for Miley, however. In the following quote, she describes how having a union was important in winning the planning time she has now: 
We used to be covered by other rooms. But then the other rooms felt that it was unfair to have their staff pulled from their classroom to cover our classroom. So, the centre hired somebody specifically to cover. They reworked everybody's schedules so that the classrooms were covering their own program time. Somebody outside was hired for our classroom. Well it was shared between two preschool classrooms, and... we are also a unionized environment, and it has changed over the years. We used to get paid time outside of work and then staff said that was not what they wanted anymore. So, our employers were, not forced, but we bargained to have it worked back into our workday.

\section{Planning time is contextual.}

The participants identify that the time of year and the contextual nature of programs affect planning time. For example, DJ talks about how planning time is different in the summer, “During summertime, it's only one ECE, but still it's an hour a day for programming." When Phoebe says that she gets "nothing in the summer, nothing", DJ replies, "That would be challenging, because even for us, one hour a day, if we have a field trip on those days, then no break." Summer field trips interrupt Gina's ability to use her paid planning time during working hours as well, but she is able to claim the hours that she works at home in these cases and is reimbursed. She explains,

In the summer time, if we do our program at home and it's consistent like for four weeks, because we don't have the staff, because of trips happening, and everything, if we go to our supervisor she will say, ok, I'm going to give you " $x$ " amount of money. I mean " $x$ " amount of hours you are going to get paid this. But now that may change, because now we have a new supervisor.

Frida talks about other contextual factors such as the difference in age groups. In response to

Kiana-Monae's description of planning in the room with kindergarten children, Frida says,

I think that's also the challenge because it depends on what age group, cause what you were saying that you [Kiana-Monae] were doing things with the children but if you were with infants, it would be harder, cause you are hands on with the babies and with the todds [toddlers]. Even simple things. Even if I need to fix a book, as simple as that, I need time on the counter. But you always have to supervise them. So, it depends on the age group as well. 
Frida also talks about what may be happening in the program as contextual factors that affect planning time. "Weeks are not the same. You might have a project, you might have a special event, you might have, like you said in the summer with the older children, you go to field trips and stuff."

\section{"It's never enough time!"}

Some of the participants who identify having paid planning time are clear that it is still not enough and that they often work on their own time. This may have a lot to do with the increased expectations of educators which will be examined more closely in the next theme. These participants also only have paid planning time once a week. Molly describes how she and her colleagues are working on their own time saying,

It's never enough time. We are all doing it on lunch break. We are all doing it at home. I'm going away tomorrow and, on my flight, I have already planned that I will be doing stuff in the air. Like I already know this and there is just not enough time.

Gina talks about how she juggles time to meet the expectations and to deal with a lack of resources. She notes,

We do learning stories, and there's only two computers. So, sometimes I'm on the subway and I'm typing away my learning stories. And that's my time. I type away, go home, email to myself, print it out, it's done. But I haven't been paid for that. But for me, when I do that, it gives me more time to program. I can go wash toys after, I can clean up my room, I can organize my bookshelf, so I think it's a little bit of a payoff.

\section{Theme 2: Expectations of educators during planning time}

As mentioned, the increase in expectations and regulations for ECEs is part of the reason for there being "never enough time". The participants expound on the general tasks that they are expected to do on top of planning their programs. What seems to take up a lot of their time, as it also took up a great amount of time in the focus group discussion, is the expectation for documentation of children's learning, specifically the quotas attached to the various forms of 
documentation required, like observations and learning stories. As well, some educators were expected to go "above and beyond" the minimum requirements set by the Ontario Ministry of Education and the City of Toronto's quality rating system, the Assessment for quality improvement or AQI (City of Toronto, 2019). The educators also talk about the stress that these regulations and expectations cause. Finally, the educators bring to light how the use of technology to help with documentation creates its own set of challenges.

\section{Too much to do}

The AECEO (n.d.) describes the current state of the ECE workforce as experiencing a professionalization gap created by a steady increase in regulations and expectations for professionalization without an increase in time and resources to meet the expectations. The participants in this study provide a detailed picture of these expectations. In the following quote,

Miley describes what other tasks she is obliged to do during her planning time saying,

During my planning time, it's writing observations, filling in program sheets (AQI expects $\sim 45$ planned activities/week for a preschool classroom.....!!!), birthday boards, updating lists (parent names, small groups), photo documentation, changing toys/books, changing displays, researching activities, researching parent resources, ordering materials, replenishing materials on shelves, physically going to stores to buy things, ensuring AQI requirements are up to date (i.e. changing photos for visual schedules), sorting photos to make sure parents get a USB with all their child's photos when they leave (our centre does no use any Apps to communicate with parents.

While Espey D describes all the other things that interrupt her planning time,

Phone calls from parents or staff in other rooms, questions from staff; children waking up; sometimes no planning - just personal errands, etc, etc, etc. The list goes on full of a whole rigmarole of things taking away your time to plan. Sometimes the person covering you is late, it's a busy time - like lunch time, or putting the beds out and it's just not possible to get out of the room on time. I've had fire drills during my planning time.

\section{Documentation, quotas and going above and beyond}

While this study is concerned with planning time, it is clear from the participants' discussion that documentation is equally as important and time consuming as planning. It's 
interesting to note that of all the participants, Espey D is the only one who was given time specifically for documentation, while her planning was done during the children's sleep time. The participants refer to various types of documentation that they are expected to complete, such as taking pictures and writing observations, blurbs or highlights, writing learning stories, and writing on charts. They also describe adding the pictures and observations to children's portfolios and sharing them with families either through email or apps designed specifically for this purpose. The participants refer to two popular apps, HiMama@ and Storypark@ as the ones they use to share observations with families. These apps allow educators to send a picture of a child along with a small written anecdote about the picture that describes what the child is doing, learning, practicing etc. These apps also have the option of making connections between the picture and observation and the Early Learning for Every Child Today (ELECT) document's Continuum of Development. The participants also talk a lot about the quotas that are required for the documentation. The $A Q I$ requires that educators document one observation per child per week and share it with families (City of Toronto, 2019). There is no official requirement for learning stories. However, some supervisors require their staff to go "above and beyond" the quotas.

Only one of the participants, Phoebe, seems to have reasonable expectations. She says, "We do two observations per month per child, and we document using tablets and the kids document themselves or other kids." Frida, however, is expected to go above and beyond the quota. She states, "In my work it was three observations per child per week. We have fifteen toddlers, three staff, so we split. So, we have five in each group to make it easier." For Frida, this means that, given the number of children in her program, the staff are writing altogether 45 observations every week. Each staff is writing fifteen observations instead of five, which is the 
minimum requirement. Frida knows that this is not realistic and says, "I refused to write three observations per child per week because even fifteen, I cannot guarantee." Molly also discusses documentation and quotas as well as the expectation to go above and beyond saying,

We do twenty observations. I have 10 toddlers in my program, we do twenty observations [per week]. Criteria [the previous version of $A Q I$ ] only asks us for 10. On the program plan they only say, "show some". We do twenty observations and every single observation has to be on the program plan. Which is not required, but it's required by our centre. And we have said, "no this is way too much". Especially now with the system with the tablets and the pictures. And they say, "No this is what we are doing. We are not doing what other centres are doing. We are doing above and beyond because we are who we are". And you can't get more than a five [rating on $A Q I$. No matter what you do, you can only get a five. So, me doing extra is not going to make a difference.

Frida challenges the idea of quotas and the narrative of going above and beyond the expectations.

She states,

Well what I hear from your stories and similar to what I have heard in my workplace, is this stories that is as old as time. When you [Molly] said, "Oh we have to go above and beyond because we are who we are". And I think they are telling us the same stories which are not true, because that doesn't show quality. That doesn't really show quality. I can write an observation, a meaningful observation and really pay attention. I engaged with the child. I took the picture. I remember the moment. I had time to write the dialogue if there was dialogue. That is more meaningful than writing twenty.

Gina talks about the quotas that are required for the program plan and how despite all the time put into writing it, it rarely all gets implemented. She explains,

I don't find that I do maybe even a quarter of my program. I'm just talking about the program sheet. It's the language, the cognition, the science, the music, you know we have to set up outside, we have to have 4 gross motors a day, 3 natures, extended learning activity, the social and I forget what the other ones... I can't do that every day. I don't even do $25 \%$ of what's on my program.

Gina also describes the quotas they have for learning stories. She says, "We have to do eight learning stories per child within that year or less than a year, before they move up to the next room and we have twenty children. Well we were supposed to do two a month per child." She also feels that this is unrealistic saying, "I can't do two a month per child. I'm more 
spontaneous.” Miley accurately points out that, "Learning stories also aren't in AQI.” DJ's

account of "above and beyond" expectations for documentation highlights the complexity of how these expectations are entangled with other expectations and logistics. He states,

We strive for above and beyond the standards, even above the $A Q I$. We do highlights, weekly and we do blurbs. We get an hour. That hour it's including washing toys, and it falls between 1-2. So, the children tend to be sleeping, however it's in transition period for the new toddler coming in the room.

He then describes how he and his team brought the issue to the supervisor and were told to delegate some of the work to the ECA (early childhood assistant). Miley objects saying, "if it's a unionized environment they are not getting paid to do programming.” DJ agrees saying,

And that's the problem. It was a non-profit and non-unionized. And now the ECA was not quite happy because they are doing something that is not in their job description and they get paid less.

DJ describes how he and his team went back to their supervisor and after a year were finally successful at reducing their workload. He says, "So now we do all the minimum according to the $A Q I$ just to meet the five. And we do everything online now." In the following quote, Frida questions the numbers and the quotas and makes a good point about what they really do:

What I don't like is the number, because the number is like picking it out of a hat. Where does this number come from? What does it mean? Why is it 3? Why is it not 4 ? Why not 2 ? Right? And show me in my job description that it says 3 . It doesn't say. It only says record observations of children. There's no number. By establishing a number also, they stop our creativity.

\section{Stress}

Taken together, the expectations of too much to do, documentation and quotas and going above and beyond demonstrate some of the causes of the stress that are documented in the quantitative literature about ECEs' poor working conditions (Blochinger \& Bauer, 2018). The participants in this study also talk about the stress related to these expectations. Gina says, 
Our program really isn't reflecting pedagogy or learning through play. It's learning through rules that have come up with that we need to show that they are learning. That's more stress on us, more stress on the kids and it's difficult for them.

Kiana-Monae feels like she cannot actually do her job because planning time is in her job description, but she doesn't really have any planning time. She reasons, "That's an expectation, but then I can't meet that expectation cause there's no time scheduled in the day to meet that expectation." Trisha describes the stress of the expectations coupled with the lack of planning time with her teaching partner stating,

We have a full-on Kindergarten curriculum that we are following. So, we are doing math We are doing language. We are reaching out for writing and again planning time is an issue and the numbers are an issue in our Kindergarten programs. We have 28, couple diagnosed, no EA support. It's stressful and again, it's like you are always planning on the fly, "Hey you are going for prep? Can you print that out?"

Finally, Frida articulates the stress from all the paperwork and the confusion about expectations. She explains,

It's just extreme paperwork; portfolios, charts, and observation. Why do I have to write on charts, a comment when I wrote an observation that day on HiMama $\odot$ ? And why I have to write twice? Why AQI says that I have to have it in a portfolio, which blows my mind but anyways, it says different things.

She captures the frustration and redundancy that result from the way quality assurance analysts interpret the expectations saying,

The observations, we print it from HiMama $\odot$. There's a picture of the child doing art, there's an observation that's in the profile. We were told [by $A Q I$ ] you need the picture of the child doing the art separately. There's a lot of things that, you know, as much work as you're doing, when it comes to these things it's like you feel discouraged, because this job is already stressful. You are doing the best with what you have.

Frida further questions the discrepancy between policies and reality and Trisha remarks on how similar everyone's experiences are despite being in different settings.

I find that all these policies, whether it is AQI or How Does Learning Happen? and they are saying all these beautiful words and all this and we know, in an idealistic world that's how it's supposed to be. But someone writes this, and when it is translating to practice, 
they don't count all these issues that we are talking about, right? So, then managers or directors translate that according to whatever they also understand. Cause you see all of us here, we're being told

Trisha: We are speaking the same language

Frida: That's right. So that puts us all the pressure to us.

\section{Speed and Technology}

One of the ways that the early childhood sector has evolved to meet the increasing demands and pace of the work is to introduce technology and apps to make documentation and communication with families faster and easier. It also helps to provide proof that the work is being done. However, technical fixes do not always solve the problem and often bring with them a whole host of other problems to negotiate. The participants discuss the different challenges they faced with technology and how it shapes the learning and documentation in their programs.

Kiana-Monae talks about why she had to stop using a tablet to document. She explains,

I was using technology and then I stopped using it in February 'cause I was just behind a screen and I wasn't able to assess any of the children, because I didn't know where they were at. The entire day was behind a screen, and that was difficult. I was just communicating with parents but I felt like the children weren't benefitting and so I just stopped doing that completely.

Molly also feels like she spends "more time behind a camera and a tablet sometimes than we are with the kids". She shares that they have recently started using tablets and have exchanged their classroom phones for work-specific cell phones. She explains how the addition of new technology requires new routines to be worked out. Molly discusses how using an app called Storypark@, makes writing the blurbs that go with the children's pictures easier but in the following quote, highlights a number of issues that arise with technology:

Now we have to run around taking pictures of kids all day long and hope for the best. And you get duplicates of pictures, because kids only do so much for a picture. And then you have to write a blurb. So, to us that's a little tedious but, you know, we do it. And then we try and download our observations, to this app and the Wi-Fi is horrible. 
Molly also describes how some of her colleagues stage pictures with children because they have maybe missed the moment when they ran to get the camera or tablet. Frida points out how technology also interrupts children's play saying,

And under many circumstances you are actually interrupting their playing because children get distracted by the iPad, and then they stop. They stop right away, or they come behind to see and I have to stop because now the moment that was precious is gone.

In the following quote, Miley clearly sums up the entanglement of time and expectations and alludes to notions of compliance and resistance:

Yes, it is ideal to have planning time in the day. I think there's a lot of the work that we do, that we're expected to do all kinds of things. We're expected to be cleaners, to be planners to be entertainers, that there just isn't enough time no matter how much planning time you give anybody. You can't do it. But I also don't know how much of that comes from a certain amount of the expectations being put on us. And 'cause we are just such a pleasing field, that if someone asks you "yeah sure, I can do that, I can do that, I can do that!" And then when does anybody say stop, I can't do that.

\section{Theme 3: Resistance}

What is most intriguing in the stories of the participants are the ways in which they question and resist unrealistic expectations within the rigid systems in which they work. They find cracks and omissions in the regulations and in their job descriptions to be able to say, "No, I won't do that." They also have different reasons for resisting. This is evident in some of the stories already shared, like the way Frida refused to write three observations per child per week or the way that Kiana-Monae stopped using the technology in the classroom because it interfered with her being with the children. Gina is expected to do two learning stories per child per month. She resists this expectation saying, "I can't do two observations per month. I'm more spontaneous." When another staff questions why a child does not have learning stories for June and July she says, "I can't work like that. I'm more spontaneous." Gina illustrates how she and 
her co-worker take lots of pictures and do their best to type up their learning stories so that by the time a child has been in their room for two months, she has completed her quota. Gina explains how she defends her practice with her supervisor saying,

So, my new supervisor, I don't know how it came up, but anyway I said to her, 'I can't do two observations per month". I said, "I'm more spontaneous and my work is done, I don't see a problem". From what I told her, she hasn't come back to me and said that that was a problem. So, we'll see what happens in the future.

Trisha also resists by abandoning the daily schedule in order to comply with the pressure to have the Kindergarten children ready for grade one. She shares,

Someday we just decide in the morning, between me and my partner, ok today you are just gonna read. Let the heaven fall down. Unless until there's fire or somebody's head is cut off, we are gonna read, because we have to send them to grade one reading a certain level. And they are expected to sit in their chairs.

Phoebe and Frida's resistance seems grounded in their confidence in setting boundaries for themselves and not stressing themselves over unrealistic expectations. Phoebe encourages others to do the same saying,

It doesn't have to be perfect. You know? You have to sign this, you have to fill this out, fine, do it but it doesn't have to be 20 sentences. It can be 2 sentences, you know? Like give ourselves a break.

Pointing out that learning stories are not in her job description, Frida says,

With this learning story, it's the same thing. It comes back and forth every so often, that we need, at one point it was one learning story per week, not per child. We just laugh. Really this is not realistic. Yeah, but I don't stress to be honest because again, in my job description there is no learning story either. My job description hasn't been changed in years. If they want to evaluate that job description again, I am glad too.

Molly illustrates how her colleagues, however, fear being penalized if they speak up. She explains,

I have staff that go in the office and say ABC and I tell my staff, you know, document it. When you talk to the office now you email them back and say, "per our conversation, I told you I cannot do this. I don't have enough time. I need support." And that way you have it. And then they can't come back to you and say, "why is your job not done?" "I 
already told you, I can't do it." But they still struggle, and they don't do it because they are scared of being penalized.

Molly describes how not meeting expectations is deemed a "work performance issue" by her supervisor and that the penalty is being "written up". Frida notices that the expectations are not necessarily coming from the parents. She says, "The rating with the $A Q I$ is a lot of pressure and it's not so much from the families." Molly agrees, "Our parents technically would say don't worry about it. It's not that it's the parents. It really is the office." DJ comments on the disconnect between management's vision and early childhood educators. He notes that he and his team feel a lot less stressed now that they have successfully had their workload reduced. He encourages others not to give up saying,

It takes time but however my co-workers and I we feel a lot less stressed over the past year because we changed, we cut off all the work. So, don't give up and just get together and, you know, keep fighting and

Trisha: Strength in numbers

DJ: Yeah. One day they will listen. That's my point, yeah.

\section{Theme 4: How educators envision planning time}

The purpose of this study is to make educators' voices heard about the challenges they face with planning time. The findings in this theme communicate how the early childhood educators in this study envision planning time. The participants speak about what they want and what planning time means to them.

\section{What educators want}

The final question that I asked participants in the focus group was what they hoped planning time could be. These early childhood educators want planning time to be:

\section{Paid.}


Planning time should be paid because it shows that we are, we don't just like wake up and become ECE. We get so much training. We have to be licensed. We have to do CPL [continuous professional learning]. So, that shows the respect in our field. And it should be paid because it demonstrates that it would reduce all the high turnover rate in the organization. That would reduce the stress from the staff. - $D J$

\section{Daily and ample.}

I would be off the floor completely for at least an hour. That would be an hour every day. At least an hour every day or 40 minutes every day. - Kiana-Monae

How is it fair to be held to these incredibly high standards while trying to be taken seriously as educators when we don't have the ample time and resources to complete what's set out before us?" - Espey D

\section{Flexible.}

Planning time should be flexible. First of all, it shows trust within the organization. I feel like if you decide to hire a trained ECE, so you should give them flexibility. - $D J$

\section{Time to think and discuss together.}

Quality is meeting with my colleague and sit off the floor at least an hour and really discuss, really discuss. - Frida

Every child has different needs, so which child needs what, you have to really think it through. -Trisha

It is VERY hard to think critically when given such a short amount of time (if any) filled with distractions, but having high expectations put upon you to complete it with exceptional quality. I would be helpful to have time to talk about the plan with your colleagues and collaborate for your classroom as a whole. - Espey D

The early childhood educators also want a revision of government regulations. Frida explains,

First of all, I would revise all those expectations that at a governmental level they have done on us, because if I wanted to do paperwork, I would have been a secretary or administration or something. Like, they call it quality, but what is really quality, because I think it's just really moving away from what it is. And reducing all the paperwork that is involved and then I will have more time to do planning and I will have more time to do all the good things that I need to do with the children. Who are we making happy? Are we really fulfilling the children and the families or is it a government outcome? The agency that you work for? Who is it? It's a competition. Who is doing it better?

\section{What paid planning time means to educators}


The early childhood educators in this study know what paid planning time means to them. DD says, "Yes, planning time is the time which is very important to run the day or the whole week smoothly. If it's a paid, then everyone will do their work honestly.” DSSD says, "Paid program time will create less stress for RECE staff and give more quality time when working with children. This will impact general working conditions- less stress, happier staff, higher quality of achievement." Miley and Frida both see planning time as critical in recognizing educators as professionals.

Paid programming time is extremely important to me. It contributes to being a professional and allows me to create intentional activities that are researched and that support the learners in my group. Having paid programming time improves my working conditions. Allows me to put effort into my planning that truly connects to children, rather than just meeting expectations. -Miley

They don't see us as professionals because professionals would get time to plan, at least a certain amount of time with your room partner to really plan for the children. What about us? It comes down to us and they don't think quality is come from us. - Frida

Finally, I had intended to share some quotes about time with the participants during the focus group discussion and have them respond. Ironically, as there wasn't time to do this during the focus group discussion, I included the quotes in the supplementary questions sent to the focus group participants. I would like to share one quote and response that I received. In response to the following quote about time:

Listening as time, the time of listening, a time that is outside chronological time ... [ I]nterior listening, listening to ourselves, as a pause, a suspension, as an element that generates listening to others but, in turn, is generated by the listening that others give us. (Dahlberg, \& Moss, 2004, p.99)

Miley wrote,

If I could just have more time to listen, to hear the heartbeat of the classroom and the individual children. The demands of $A Q I$ don't always allow for the child's honest interests and areas of growth - it's taken some skill and creative programming on my part to find places in the program requirement to plan for the social emotional development of children. Often, I'm looking to see who passes through the sensory bin to make an 
observation to meet the requirements of 10 activities planned for the sensory area instead of truly spending time to watch and listen to what the children are figuring out. Why does planning have to change every week?

\section{Summary of the findings}

My analysis of the focus group discussion and the written responses from RECEs from a variety of working contexts reveals that the educators have varying complex configurations of planning time. The similarities in their experiences with planning time despite the varied contexts in which they work further validate the authenticity and trustworthiness of the findings. Four themes emerged from the analysis which describe what planning time looks like, the expectations of educators, how educators resist and how they envision planning time. The first theme gives detailed accounts of the complexity and differences in how educators experience planning time. It also explores the contextual nature of planning time and that there is never enough time. The second theme focuses on the increased expectations of educators bringing to light the intense focus on the high expectations for documentation and the quotas attached to them, along with expectations to go above and beyond these quotas. The stress caused by these increased expectations is explored as well as the use of technology, with its own set of challenges, as a solution to mitigate the tension between time and expectations. The third theme examines how educators resist stringent expectations in various ways and for various reasons. The fourth theme lifts educators' voices as they speak about how they envision planning time, what they want and what it means to them. The ECEs' perspectives on planning time are valuable since they foreground the lived experiences of educators. The next chapter will discuss the findings in relation to the existing literature and will offer a reconceptualization of the findings through a feminist post-structural and queer time lens. 


\section{CHAPTER 6. DISCUSSION AND CONCLUSION}

This chapter discusses the findings of the study and their possible implications for future research, policy, advocacy and practice. First, it discusses what has been revealed in the findings that was previously unknown or missing from the literature. Then using feminist poststructuralism and queer time this discussion deconstructs the findings to reveal how ECEs' time, expectations and subjectivity are deeply entangled with and constructed by neoliberalism and developmentalism, suggesting the real cause of educators' stress. Finally, it examines how the educators in this study are resisting within these systems and what is needed to resist the systems altogether.

In keeping with the tenets of critical qualitative inquiry, as proposed by Cannella (2018), the findings chapter engages with the marginalized voices of early childhood educators. This discussion of the findings now works to activate the other proposed tenets of critical qualitative inquiry that suggest engaging with structures of oppression and positioning research toward social justice and activism (Cannella, 2018). Due to the scope of the study, I am unable to engage directly with structures of oppression. However, I engage them indirectly in this discussion by noticing the discourses and structures of neoliberalism and developmentalism revealed in the findings. Similarly, though I am unable to participate directly with the educators in this study acts of social justice and activism, I present this study as a site of potential activism and suggest tools of resistance readily accessible to educators.

The findings in this study reveal that planning time is much more complex than was previously known and they contribute significantly to an understanding of planning time that is missing from the literature. Past quantitative studies merely depict the percentages of educators who have paid planning time (Child Care Sector Human Resources Council, 2013; Doherty et 
al., 2000), and only a limited number of qualitative studies briefly capture ECEs' experiences of planning time within the larger context of working conditions (AECEO, 2016b; Boyd, 2013). There are no studies that focus exclusively on the educators' perspectives on planning time and advocates who call for paid planning time for educators are not specific about what that, in effect, means (AECEO, Decent Work Task Force, 2017; Urban, Vandenbroeck, Laere, Lazzari, \& Peeters, 2012).

Based on the themes that emerge in the findings, what planning time looks like, expectations of educator during planning time, how educators resist and what educators want, this study suggests an amount and frequency of time that is adequate for educators to meet the expectations imposed on them. The educators in this study who report having daily ample planning time, i.e. at least a half hour to, ideally, an hour everyday, also speak the most positively about their experiences and report having less stress and feeling "lucky" and "spoiled" by the amount of time they are given for planning and documentation. The educators also reveal the need for having planning time together with their educator partner. Those that are forced to plan individually are limited in their ability to effectively plan and communicate with each other about curriculum making and documentation. The educators also reveal that having autonomy and flexibility in how they use their planning time is important. It helps them adjust to the contextual and complex "goings on" in a childcare program and contributes to feeling respected and being treated as a professional.

The findings further suggest that just having daily ample time together with their partner is not enough. It must be accompanied by reasonable expectations, both from government bodies and employers. In fact, the findings in this study uncover that employers play a significant part in increasing expectations for educators. It is important to hear about and document the increasing 
expectations imposed on educators so that educators are taken seriously, and the importance of planning time is no longer overlooked. I argue that adequate time and reasonable expectations are still not enough for educators, as long as early childhood education remains situated in a neoliberal market system and dominated by the single story of developmentalism.

\section{Noticing neoliberalism at work}

Noticing neoliberalism as a capitalist and patriarchal system in early childhood education is critical to being able to resist it (St. Pierre, 2000). Neoliberal structures of power as well as discourses of competition, individuality and consumerism are evident in the findings. Furthermore, critiques of neoliberalism such as the time-space compression (Tronto, 2003) and the regulatory gaze (Osgood, 2006) are also revealed. First, neoliberalism and early childhood education's location in the market system are borne out in the complexity of the varied experiences of planning time the participants in this study report having: some more, some less, some every day, some once a week, some are paid for time they work at home and some have paid planning time only because they pushed for it and it is still not consistently given. While complexity and local decision making are usually desirable, especially from a critical perspective, the complex and inconsistent configurations of planning time reported here demonstrate how decisions to give educators planning time are based on local contexts tied to budgets, fees, salaries and operating costs and which are currently driven by neoliberal market forces.

Furthermore, the surprisingly unexpected fact that most of the educators in this study report having some amount of paid planning time, presents a tension in the findings compared to the literature. In 2013, only about $43 \%$ of ECEs had paid planning time (Childcare Human Resources Sector Council, 2013), compared to 54\% in 1999 (Doherty et al., 2000), suggesting a 
declining trend. Also, considering the location of early childhood education within the current neoliberal market system, which has arguably worsened wages and working conditions for educators, I had anticipated that most of the participants would not have paid planning time, as providing paid planning time is expensive and unaffordable for most childcare centres to implement without an increase in parent fees.

So, why is it that most of the educators participating in this study have some amount of paid planning time, when this would seem unlikely within a neoliberal market system? I speculate that it may be connected to the increased workloads of educators who are pushing back and demanding time, as evident in Molly, Miley, Frida and DJ and Gina's accounts. Miley also had the support of her union, collective strength, in demanding time. Frida is confident in resisting the pressure to meet expectations that are not in her job description because of her unionized status. I also wonder how paid planning time is connected to measurable quotas for producing documentation. In an neoliberal system, it makes sense that time, which can be accounted for, is valued. This would be in line with Osgood's (2006) discussion of the masculinized nature of neoliberalism and regulations in early childhood education.

The findings in this study reveal how the neoliberal discourse of competition is taken up in a very interesting way and perpetuated most intensely by employers. Some of the educators discuss their employers' expectations that they go "above and beyond" the minimum requirements for documentation set by the government, by doubling or tripling the quotas. I find this curious, but not surprising, considering how this discourse works within the market system. As most of the centres that the educators in this study are working in are non-profit, the push to go "above and beyond" is not necessarily financially driven but rather driven by a quality discourse that creates competition to be the best which indirectly affects financial viability. This 
is evident in Molly's comment about her employer's rationale for going above and beyond, "We are not doing what other centres are doing. We are doing above and beyond because we are who we are." In the city of Toronto, the quality assurance ratings of individual centres which are publicly posted likely account for this sense of competition to be considered a "high-quality" centre. This in turn makes the centre more desirable to parents as consumers, which maintains enrollment in the centre and thereby maintaining the centre's financial stability.

The findings however, indicate that this may only be the case for parents and families when they are looking for a childcare centre, however, once their children are in the centre, their influence on expectations for educators may change as suggested in the findings in this study. Frida and Molly both describe how the families that they interact with are very understanding about their workload and want the educators to be engaging with their children as a priority over paperwork. Frida says, "The rating with the $A Q I$ is a lot of pressure and it's not so much from the families." Molly says, "Our parents technically would say don't worry about it. It's not that it's the parents. It really is the office."

There is a deep question and tension about how quantitative measures are used to define and describe notions of quality. The limitations of quality rating scales, and therefore the discourse of competition, are exposed in the findings of this study. Molly points out that despite the competitive expectations for her and her staff colleagues to go above and beyond the quotas for documentation (doubled quotas), there is a limit to the score that she can get. She says, “...you can't get more than a five [rating on $A Q I]$. No matter what you do, you can only get a five. So, me doing extra is not going to make a difference." Frida's comment reveals a critical take on quality rating scales, stating,

That doesn't really show quality. I can write an observation, a meaningful observation and really pay attention. I engaged with the child. I took the picture. I remember the 
moment. I had time to write the dialogue if there was dialogue. That is more meaningful than writing twenty.

Here, Frida demonstrates the incommensurability that Osgood (2006) explores, between a masculinized neoliberal system that values competition and the unquantifiable nature of relationships and caring that are central to being an early childhood educator. Tronto (2003) and Adam (2006) agree that time is gendered, and that women's time is not compatible with commodified, market time, arguing that how time is organized in caring professions that are predominately female, needs to be addressed from a feminist perspective.

Another source of competition and increased expectations uncovered in the findings comes indirectly from some early childhood education pre-service training programs that are teaching students other forms of documentation and expecting them to complete this documentation in their field practicum. Frida, Gina and Molly specifically mention learning stories as one form of documentation that is not required by government regulations either provincially or municipally, but which they are expected to complete because of an expectation to model this form of documentation for early childhood education students. The educators in this study identify that learning stories are separate and in addition to the expectations for documenting observations of individual children. This expectation seems to carry an assumption that documenting using learning stories corelates to quality due to its connection to the currency of college training programs.

Employers have also attached their own quotas for learning stories that educators are expected to meet. Frida mentions that she is expected to complete one per week (on top of her employer's expectation to triple the quota for documented observations of children) to which she responds by saying, "We just laugh. Really this is not realistic." Gina is expected to complete eight learning stories for each child in her program within a school year, or approximately one 
per month per child. She also finds it difficult to create these pieces of documentation according to this schedule. "I can't work that way" she says, "I'm more spontaneous." The lack of consistency in the expectations of educators, specifically regarding documentation, reveals the spaces in which educators are potentially exploited but which could also be points of resistance as demonstrated by Smith and Campbell (2018). This interplay between power and resistance is identified in feminist poststructuralism (St. Pierre, 2000) and will be further explored later in this chapter.

Along with the discourses of competition, individuality is also apparent in the findings, most notably in the fact that many educators do not have time to plan together with their teaching partners. Trisha and Frida comment on how this limits their ability to communicate effectively about planning for their programs. and impacts their ability to function fully in their roles. Consistent with recent literature about full day kindergarten (FDK) teaching partnerships (Underwood et al., 2016), the educators in this study who are working in FDK programs also report not having time to plan with their teaching partner and expound on the frustration that this causes. For Trisha, it also contributes to a feeling of being rushed as she describes, “... you are just, like flying. You are talking on the fly."

While educators are legally required to plan curriculum and document children's learning, the government is not accountable to educators for providing time to accomplish these expectations. The findings reveal that the onus for arranging planning time is on individual centres, supervisors and parent boards, who in turn often leave it up to their staff to figure out, demonstrating how neoliberalism abdicates responsibility and leaves the decision making up to the individual. This is seen in the findings in Miley and Frida's accounts of educators supporting each other to be able to leave their program to plan and how this arrangement breaks down and is 
unsustainable. It is also evident in DJ's account of being told to delegate some work to the ECA in his program which also did not last long.

Furthermore, neoliberalism's individualizing agenda is evident in the way it transfers not only responsibility but also consequences to the individual educator. This is starkly revealed in Molly's account of being told that if she cannot complete the 20 observations that her employer expects every week that, "[i]t's a performance issue. If you cannot do it, we will write you up." Molly also describes how her educator colleagues do not speak up about needing more time to meet expectations, for fear of being penalized.

Finally, documentation itself is an individualizing practice. Embedded within the childcentred philosophy and practice of early childhood education in Ontario (and in much of the English-speaking world) documentation focuses on the learning and development of each individual child in relation to discreet, categorized domains and skills of human development. The educators in this study extensively discuss the time they spend documenting individual observations of children much like the educators in Smith and Campbell's (2018) study. This individualization of children through documentation works to perpetuate and reproduce the discourse of individuality.

The expectations for producing documentation are also linked to neoliberal consumerism. Apart from the fact that the location of early childhood education within a market-based system positions parents as consumers (Halfon \& Langford, 2015) of childcare services, documentation of children's learning is also presented to families in a consumer fashion, neatly packaged, and easily digestible within tailored apps. The educators in this study describe the "rigid production schedules" (Wein, 1996, p. 377) of documentation that they are expected to keep as well as their use of apps that make it "quick and easy" to send documentation to families. In a neoliberal 
context, the documentation that educators produce for the quick and easy consumption of parents as evidence of their children's development also serves as proof of educators' expertise and verification that they are meeting expectations for a definition of quality. The implications of documentation will also be explored further from a developmental perspective and in the context of resistance through pedagogical documentation later in this chapter.

Time as a commodity, measured by the documentation that educators produce in order to legitimize themselves as professionals, is also part of the discourse of consumerism in early childhood education. This study confirms that even educators who have paid planning time still work on their own time, which lowers their wages and further devalues their time. Phoebe is the only participant who does not describe using her own time to complete work. She also reports having a half hour everyday of planning with her partner, which she states contributes to accomplishing her work quicker as they work well together. Time as a commodity also leads to a speeding up of time to keep pace with demands for production. In the literature, reconceptualist scholars have critiqued the tyranny of the clock in early childhood settings (Kummen, 2010; Pacini-Ketchabaw, 2012; Rose \& Whitty, 2010; Wien, 1996; Wien \& Kirby-Smith, 1998). Though the participants do not speak directly about clock time in the same way, they do point to the increased pace of their work and the subsequent introduction of technology to make the work of documentation easier and to help it go faster.

Rose and Whitty (2010) note the speeding up of time that comes with an increase in expectations within neoliberalism. The educators in this study also describe feeling this speeding up of time. Trisha refers to working "on the fly". The increasing expectations for educators to do more in the same amount of time is what Tronto (2003) refers to as the time-space compression. Gina describes working on her own time intentionally as it affords her more time at work to do 
other tasks. She calls it a "payoff". Molly describes how on her vacation she has already planned out what work she will finish during her flight.

Dahlberg, Moss and Pence (2006) also allude to technological solutions to the time-space compression stating, "We live in a world that is increasingly time-governed, driven by new technologies and demands for increasing productivity. We are saturated with information. We demand and expect instant answers and quick fixes" (p, 17). Most of the educators in this study describe using some form of current technology for documenting children's learning and development. Gina remarks that her childcare centre is looking into some apps to make the documentation faster and easier.

However, the quick fixes that technology promises are obscured by the new challenges and problems that it brings. The educators in this study identify the most invasive technological solution to be the use of tablets or iPads and apps to create and share documentation. For some of the educators in this study, most of their documentation takes place on a tablet or iPad. While they admit that apps and tablets do generally make taking and sending pictures faster and less expensive than printing pictures (when the $\mathrm{WiFi}$ is working), they also report an increased expectation for taking pictures which negatively shapes their practice and ways of engaging with children. Molly and Kiana-Monae describe being behind the camera for long periods of time. Molly describes how her colleagues will sometimes stage pictures with children because they "missed the moment" while running to get the camera. She also shares how children are resistant to being staged and often refuse to "do it again". Frida rightfully questions the purpose of this kind of documentation and whether it is actually meaningful and authentic. She further notes that having a tablet in the room interrupts children's play because they become distracted by the technology. The educators' descriptions of the use of technology suggest that their time with 
children now revolves extensively around documentation and less around relationships. Their descriptions also reveal that expectations for producing documentation are interfering with their ability to be engaged with children, echoing the incommensurability of neoliberalism with the centrality of relationships within the care work of early childhood educators (Langford et al., 2017; Osgood, 2006; Tronto, 2003).

Noticing neoliberalism in quality rating scales, quotas for documentation, and the use of technology in the educators' perspectives on planning time in this study is consistent with Osgood's (2006) critique of the regulatory gaze and its effects on structurally and socially constructing the image of the educator. Outwardly, as the educators in this study describe working to achieve high quality ratings and to meet quotas for documentation, often using their own time, they are being structurally constructed as technicians (Moss, 2006) who merely apply the technologies toward predetermined outcomes. Frida questions the random numbers as quotas that are attached to documentation pointing out that "by establishing a number, they stop our creativity." The construction of the educator as technician is helped by the neoliberal discourses of competition, individuality and consumerism which set up compelling expectations for educators to meet and to be considered a "good" educator. Frida's description of her encounter with a quality assurance inspector's arbitrary interpretation of quality, which in this instance meant that a picture of a child doing art must be stored separately from the written observation of the picture. This example reveals how the inspector's image of the "good" educator, as one that complies with external expectations, is constructed through the implementation of disciplinary power and technologies of control. It also reveals a devaluing and undermining of the work of educators and their ability to make decisions about what documentation is and can be. 
The discourse of the "good" educator, linked to rating scales, also socially constructs the image of the educator as it becomes internalized so that educators regulate themselves. Again, as Cannella (1997) states,

The discourses and actions associated with professional institutions and practice have generated disciplinary and regulatory powers over teachers (who are mostly women) and children. Standards have been created through which individuals judge and limit themselves, through which they construct a desire to be "good," "normal" or both (p. 138).

Molly's comment from her supervisor about going above and beyond expectations because "we are who we are" is an excellent example of how discourses of the "good" educator are entangled with quotas and rating scales. Frida recognizes these as long running discourses, calling them, "stories as old as time". It can be inferred from Gina's description of being able to implement only a quarter of what she plans for her program each week, that her inability to implement everything on her program plan means that she has somehow failed as an educator, connecting again to the neoliberal value of individual responsibility.

\section{Noticing developmentalism at work}

Developmentalism is evident in the findings of this study in the educators' descriptions of quotas for documentation, experiences of documenting children's learning, standardized quality assurance measures, as well as the contextual nature and complexity of educators' planning time. Woven into developmentalism are discourses of who is a good early childhood educator or who is not.

The quotas for documentation and quality rating scales described by the educators in this study set predetermined expectations for quality, and therefore expectations for educators, in much the same way that developmental theory sets predetermined outcomes for children's growth and development. These limitations of developmentalism are most notable in Molly's 
comments, first about only getting as high as a five on the rating scale despite going above and beyond expectations, and, second, about documenting children's learning by taking pictures where she states, "you get duplicates of pictures, because kids only do so much for a picture" and in her description of educators staging pictures with children. As mentioned above, Frida's observation about how quotas and numbers "stop [her] creativity" can also be attributed to the restrictive nature of developmental theory as well as neoliberalism. The good "professional" educator is also the one who expertly applies the theories of development to children. Langford's (2007) study confirms that educators who take up developmental theories to apply are more easily considered by others and themselves as good educators.

Developmentalism's preference for simplified, standardized, categorized, universal norms that can be applied broadly are contradicted by the findings in this study that reveal planning time for educators as complex and contextual. Projects and events may be happening, or fire drills or field trips in the summer. All of these elements affect educators' time in specific, daily and local ways, demonstrating that it is important for educators to have autonomy and flexibility in how they use their planning time because it respects their ability to make ethical decisions (Dahlberg \& Moss, 2005). Educators in the study who report having limited flexibility, autonomy and time, such as Molly, Kiana-Monae and Gina and Trisha, are not able to adequately respond to the complexity of their contexts, also affecting their image as a "good" educator.

Queer time is useful in disrupting the linear nature of developmental theory that assumes a universal pattern of development, creating more complex understandings and logics of temporality (Halberstam, 2005). This will be explored in more detail in the discussion on resistance. 
Furthermore, developmentalism, as a modernist project, constructs educators and children as fixed, knowable subjects (St. Pierre, 2000), whereas feminist poststructuralism acknowledges the complexity of subjects within relationships that can only be partially known and which are not easily measured and regulated (Osgood, 2006). This focus on complexity is relevant to planning time because the image of the educator as a technician demands a different kind of time than the image of the educator as a researcher (Moss, 2006).

As the ELECT document, to which the educators in this study refer, is grounded in developmentalism, it is important to investigate how it also creates a discourse of the educator and how this relates to the findings and to planning time. ELECT positions educators as knowledgeable, responsive and reflective (Best Start Expert Panel on Early Learning, 2007). The educator in ELECT is positioned as an expert in a child-centered program based on predetermined developmental outcomes and as one who reflects internally on their own practice. The educator in ELECT is a fixed, knowable subject, measured and known by rating scales and quotas, just as children are measured against the predetermined outcomes of developmental theory. ELECT specifies that educators need time however, the time implied is organized around developmentalism and hence "rigid production schedules" (Wien, 1996, p. 377). This is evident in the participants' descriptions of applying developmental outcomes to their planning and documentation and of working to meet quotas and achieve high scores on quality assurance ratings. Thus, constructing the educator as technician (Moss, 2006), who merely applies technologies to their work; educators to whom Foucault (1979) would refer to as docile bodies.

In contrast, the image of the educator in $H D L H$ is vastly different from the one in ELECT. HDLH positions educators as researchers, engaged in critical reflection and collaborative inquiry. It goes even further in inviting educators to thoughtfully question and 
challenge the status quo (Ontario Ministry of Education, 2014c, p. 13). The educator as a researcher implies that they are questioning and curious; they do not have all the answers and they are not fixed by predetermined outcomes. $H D L H$ is grounded in relations rather developmentalism. While it does not abandon developmentalism completely, it does invite educators to think with other theories and theoretical perspectives. It can be seen as a feminist poststructural document because it provides female educators opportunities to reject the discourse of a fixed and knowable subject and to take up or create other discourses of who they are and what they do. Educators in $H D L H$ are also critically reflective, which means they are not only reflecting on their own practice, but they notice and critique the systems in which they work and the regimes of truth that oppress them. Educators in $H D L H$ work collectively and collaboratively in their inquiry with children but also as ethical and political subjects who have power to resist and take a stand against normalizing technologies of control. Furthermore, $H D L H$ challenges masculinized neoliberal systems by the very fact that it is centered on relationships, and as Osgood (2006) states, "[i]n neo-liberal discourses there is little room for emotionality or such feminine characteristics that are seemingly unquantifiable or auditable" (p, 8). ELECT creates subjects as docile bodies, but $H D L H$ intends to awaken educators to question and challenge the status quo.

Frida notices that there is something wrong with the image of the educator that is constructed by neoliberalism and developmentalism as she questions the meaningfulness and authenticity of producing documentation to meet quotas as opposed to documenting her engagement in meaningful interactions with children. She eloquently points out that quality is not an external rating but that "quality comes from us", the educators. This statement demonstrates how regulations and discourse shape the image of the educator and hints at the 
resistance to a subjectivity created through regulations. Frida rejects the discourse of quality as an external measure and takes up a discourse of quality as intrinsically coming from the educator. This is also in line with the position of the educator in $H D L H$. If, as Frida states, “quality comes from us", meaning women, this makes her dangerous, in the context of Osgood's (2006) argument that "the emotional labour ECEC [early childhood education and care] practitioners engage in engenders fear in government because it is perceived as hyper-feminine and therefore unmanageable, unquantifiable and hence impossible for the state to regulate" (p. 9).

\section{The real cause of educators' stress}

The literature identifies that educators experience a lot of stress (Curbow, Spratt, Ungaretti, McDonnell, \& Breckler, 2000; Faulkner, Gerstenblatt, Lee, Vallejo, \& Travis, 2016: Wagner et al 2013; Boyd, 2013) and that an increase in expectations with few resources and support are linked to symptoms of burnout and depression (Blöchliger \& Bauer, 2018; Roberts, Gallagher, Daro, Iruka, \& Sarver, 2017). While the participants in this study do not specifically discuss burnout and depression, they do talk about stress related to increased workloads and less time, which offers more insight into the specific issues that are causing educators' stress. The educators relate stress to the increase in rules and paperwork, especially the quotas for documentation, and achieving high scores on rating scales. Gina identifies that the increased expectations are present in her program noting that it “isn't reflecting pedagogy or learning through play. It's learning through rules." The educators also attribute stress to the subjective, make-work specifications and interpretations of quality by inspectors. They even attribute stress to the arbitrary decisions about quality and quotas made by decision-makers who are far removed from the everyday lived realities of working with children. 
The literature also points to turnover rates as consequences of stress, depression and burnout rates. The participants in this study do not necessarily discuss turnover rates, except for DJ who states that paid planning time will reduce high turnover rates. Evidence of possible turnover among the participants can be inferred in the stories of DD, DJ and Espey D who talk about leaving jobs for other positions. The length of time these participants had been working in positions before leaving was under four years. Espey D left her last position after less than a year to go back to school. Another possible reason that turnover rates were not part of the focus group discussion may be that most of the participants have worked for at least seven years and up to $30+$ years. I speculate that this is because many of the participants are in unionized jobs, which would mean they potentially have a high level of job security, seniority, good wages, benefits and pensions. It is also consistent with the study by Holochwost, DeMott, Buell, Yannetta, \& Amsden (2009) who found that workforce retention was higher for educators who had worked for more than five years. It is clear from the findings that educators are stressed due to intensified workloads with little supports and time to match the increased expectations, and that having daily ample time and reasonable expectations would address the issue of educators' stress.

However, examining the causes of stress from a feminist poststructural perspective exposes neoliberalism and developmentalism as the true causes of educators' stress in the form of the time-space compression (Tronto, 2003) and the regulatory gaze that female educators experience. I contend that in order to truly address the stress, depression, burnout and turnover rates amongst early childhood educators that neoliberalism and developmentalism in early childhood education must also be addressed as causes and resisted. 


\section{Resistance within/out neoliberalism and developmentalism}

The findings in this study reveal how neoliberalism and developmentalism work together to create discourses of who "good" early childhood educators are and what they do.

Neoliberalism individualizes and controls educators by increasing expectations and competition, keeping them too busy to think or challenge the status quo (Osgood, 2006). Developmentalism's normalizing technologies of control, stifle creativity and create docile bodies that conform to predetermined, standardized outcomes. However, the findings also demonstrate how many of the educators in this study actively resist. For example, Molly confronts her supervisor to advocate for having time during the workday to plan as well as having a half hour paid afterhours. She also encourages her colleagues to resist.

The importance of collective action and unions in resisting neoliberalism's strategy of individualizing workers is revealed in these accounts as well. Miley describes how her union bargained to have the planning time incorporated into their workday as opposed to being paid for working at home. DJ and his team actively push back for a year to get their workload reduced. While Molly, although unionized, describes her team as not very strong and she explains how they fear being penalized for speaking up, even when unionized, so they are less successful in securing more planning time.

The educators also resist by identifying cracks and omissions in their job description and in the regulations as points of resistance (Smith and Campbell, 2018) which they use to fight back against arbitrary expectations and take a stand, exhibiting ethical substance and ethical work (Cannella, 2018). Frida who is also a unionized educator, and describes having a strong team, refuses to meet the "above and beyond" expectations that are not in her job description. Kiana-Monae intentionally stops using the tablet to take pictures because she finds she is 'behind 
a camera all day" and it interferes with her engagement with the children. In all of these instances of resistance, the educators activate their ethical substance (Cannella, 2018) by taking a stand against disciplinary power, normalizing technologies of control and unethical practice.

The educators' acts of resistance are hopeful. They demonstrate that where there is power, there are also opportunities to resist and to reject discourses that create them as subjects in a masculinized neoliberal system. While Frida's questioning of numbers and quotas, "Why is it 3?” and Miley's question “When does anyone say, 'Stop. I can't do that?" demonstrate that they are beginning to critique the systems themselves, some of the other educators who are resisting are doing so still largely within the systems of neoliberalism and developmentalism. This is demonstrated in the following accounts and examined through a queer time lens. Halberstam (2005) identifies queer time as a useful framework for challenging the normativity and respectability of Western ideals of temporality. In the findings, there were two instances where the concept of queer time can be cautiously connected to the narratives offered by the participants. The first is Gina's refusal to produce learning stories on a rigid production schedule because she does not "work that way", and she is "more spontaneous". The second is Trisha's decision to abandon the scheduled routine and just read with her kindergarten children, and where she states, "let the heaven fall down!" While I recognize that Gina and Trisha are taking a stand and challenging normative expectations of time, I am also cautious about applying the concept of queer time here as they are challenging these expectations of time within the neoliberal system. They are not challenging the system itself, which queer time ultimately does. Gina, for example still meets and intends to meet the goals of having the required amount of learning stories, she just produced them according to her own timeline. Trisha as well, disrupted the normal schedule of time, but did it in order to meet linear developmental expectations for 
children's school readiness. Smith and Campbell (2018) identify these spaces as borders of compliance and resistance (p. 316). They too describe finding themselves complying with some expectations while resisting others. Tronto (2003) describes how feminists in Italy collectively changed the "city's time" so that they could access government offices during hours that accommodated their other responsibilities. I wonder how queer time may be useful in early childhood education to re-arrange time in ways that are commensurable with caring and relationships.

I am hopeful that if educators are willing to challenge normative expectations of time within systems, they will be even more willing to challenge systems and discourses once they are aware of those systems and discourses and how they are oppressed by them. The issue is that the power in systems and discourses is still invisible to many. MacNaughton (2005) encourages educators that "uncovering the invisible is the first step to challenging [dominant ideologies] and the oppressive and unjust power relations they hide and support" (p. 8). This is one of the intentions of this research study. The invisibility of systems and discourses of oppression are evident in the tenacious hold that ELECT has on early childhood education in Ontario, despite the introduction of $H D L H$. ELECT's resiliency is likely due to its snug fit within the neoliberal market system. There is a sense that educators may be unaware of the revolutionary nature of $H D L H$, in the way that is it conflated with ELECT, possibly indicating why it doesn't seem to have as much currency. This is evident in the findings as Frida refers to both HDLH and ELECT as documents espousing beautiful words, but which seem to be disconnected from the realities of everyday practice.

I believe that a closer reading of $H D L H$ with educators may reveal this document as a tool for resistance. I have previously discussed its revolutionary envisioning of the early 
childhood educator as researcher. $H D L H$ invites educators to question and challenge the status quo, stating, "[t]houghtful questioning and challenging of the status quo on an ongoing basis can help transform programs and bring out the best in children, families, and educators" (Ontario Ministry of Education, 2014c, p. 13). This echoes MacNaughton's (2003) transforming society approach to early childhood education and implies that what is needed is a paradigm shift. $H D L H$ also challenges the status quo directly by identifying developmentalism as an incomplete picture and recognizing that there are other theories that educators need to draw on. For example, it states,

How Does Learning Happen? further expands on what we know about child development and invites educators to consider a more complex view of children and the contexts in which they learn and make sense of the world around them. This thinking may require, for some, a shift in mindsets and habits. It may prompt a rethinking of theories and practices - change in what we pay attention to; in the conversations that we have with children, families, and colleagues; and in how we plan and prepare (Ontario Ministry of Education, 2014c, p. 17).

The last part of this statement suggests lines of flight (Deleuze, Guattari \& Massumi, 1987) for educators to reimagine and reinterpret curriculum making. These are spaces where there is an opening to create something new by going in a different and unexpected direction. Taking up Tronto's (2003) call to consider time as well as space from a feminist perspective, perhaps moments of flight or times of flight, like queer time, can open up new ways of organizing time in early childhood education that resist clock time and are more responsive to rhythms of caring time.

The idea of moments of flight can be found in pedagogical documentation. Smith and Campbell's (2018) use of a single journal to document the learning processes in their centre is one example of using pedagogical documentation as a moment of flight. It offered them a way to prioritize their time with children while engaging in documentation that made space for thinking 
beyond developmental theories and which challenged the status quo of neoliberalism. $H D L H$ offers pedagogical documentation as a process to imagine and engage in curriculum-making with children, families and communities that is vastly different from the current forms of documentation being practiced. Described as, "[m]oving beyond simply an objective reporting of children's behaviour, pedagogical documentation helps to find meaning in what children do and what they experience" (Ontario Ministry of Education, 2014c, p. 21). Pedagogical documentation is not a prescribed method however, and it requires time and thought and new theories to begin to be activated. One way that this is beginning to happen in Ontario is through the creation of a pedagogist network by the Provincial Centre of Excellence for Early Years and Child Care (Centres of Excellence for Early Years and Child Care, 2019). Pedagogists are being introduced to work alongside early childhood educators and,

Through deep engagement with pedagogical documentation, the calls to action of Canada's Truth and Reconciliation Commission (2015) and the values of Ontario's How Does Learning Happen? (2014), pedagogists lead pedagogical projects in individual programs and connect them to the social and cultural fabric of communities. With children, families, educators and others, pedagogists help to reimagine early childhood education as a plurality of spaces for democratic possibilities (Centres of Excellence for Early Years and Child Care, 2019).

This is an exciting prospect but one that will inevitably require that educators have time to engage with pedagogists as well as time to think, read, discuss, question and begin to change how they practice early childhood education. This new way of thinking about early childhood education is critical to transforming society in the face of climate crisis and the age of the Anthropocene. As Moss (2010) argues, early childhood educators have an opportunity to reimagine the purpose of early childhood education as an education for survival, social justice and democracy. Educators need time and space to see education as political and not neutral; as embedded within neoliberalism and developmentalism; and to start thinking and questioning 
with other theories (MacNaughton, 2003). I contend that this is a dangerous proposition; that planning time is a dangerous time and place in between the borders of compliance and resistance. And as Foucault (1983) says, "everything is dangerous" and "if everything is dangerous then we always have something to do" (p. 231-232).

\section{Trustworthiness}

The fact that the participants all came from different working contexts yet had similar experiences with planning time adds credibility to the findings. The issues they describe are not isolated to one particular individual but appear across their varied contexts. Trisha states, "we are speaking the same language." Member checking also contributes to the credibility of the study.

Participants were given the opportunity to review the findings to ensure I had accurately captured their perspectives and to provide feedback, corrections or additions to their voices and narratives. Furthermore, I have kept multiple journals including analytical memos throughout the research study as a record of the decisions I made and how I came to make certain choices. Journaling also serves as documentation of my thinking throughout the research process and as a practice of reflexivity. Finally, analyzing the focus group data and written responses through more than one theoretical framework, feminist poststructuralism and queer time add to the trustworthiness of the study by offering multiple perspective with which to view the findings.

\section{Limitations}

This study is limited mainly by its small sample size and its qualitative nature. It is therefore not generalizable, nor is that its intention. The sample is also skewed toward educators that have paid planning time and who are mostly working in unionized environments. This presents a bias toward a certain kind of educator and may explain why many of them demonstrated some forms of resistance. While at first, I had anticipated that more of the 
participants would have unpaid planning time, similar to my own experience, their narratives about having paid planning time offered a depth of insight that was unfamiliar to me and provided valuable information about what planning time for educators should look like. Furthermore, not having any current information about the percentage of educators in Ontario with paid planning time adds to the tension in the findings about the majority of the participants having paid planning time. Either this data needs to be collected again or the Ontario Ministry of Education needs to implement a strategy for ensuring educators have paid planning time. (see recommendations below).

The study is also limited in the design of using a focus group and my limited experience in hosting this form of discussion. While the focus group discussion was rich and complex and provided a wealth of information, the logistics of focus group dynamics meant that some participants were not as active in the conversation as others. In hindsight, I would have liked to be able to bring those that were quieter into the conversation in a more robust way. Also, in reviewing and transcribing the data, I discovered many instances where I would have liked to ask probing questions to elicit more detail and explanations.

Another limitation in this study is that I was not able to fully activate all of the tenets of the critical qualitative approach to the methodology that I chose to work with. According to Cannella and Lincoln (as cited in Cannella, 2018) critical qualitative inquiry should strive to "expose the diversity of realities; engage directly with webs of oppression; reposition problems and decisions toward social justice; and join in solidarity to create new ways of functioning" (p. 345). I was able to expose the diversity of realities by engaging with the marginalized and silenced voices of predominately female early childhood educators. I engaged indirectly with webs of oppression, by applying a feminist poststructural and queer time framework to the 
research findings. By doing so and exposing the regimes of truth that oppress female educators, I was able to reposition the issue of planning time toward social justice. Due the small scale nature of this study, I was unable to join in solidarity to create new ways of functioning, however, as an educator who experienced not having planning time, I expressed a sense of solidarity with the educators in this study and I have positioned this study as a site of activism in the hopes that educators may be inspired to create news ways of functioning.

\section{Recommendations}

Recommendations for future research include broadening the scope of this research to include early childhood educators across Ontario. As different municipalities and regions have different local expectations it would be interesting to understand these differences compared to the findings in this specific location.

Considering the small scale, qualitative nature of this study, I present preliminary and modest, yet compelling recommendations for advocates and policy makers to consider regarding the implementation of paid planning time for early childhood educators. Planning time must be daily and ample, at least a half hour to an hour. Educators must have autonomy and flexibility in how they use their planning time and they must be able to plan together. An implementation of planning time must also be accompanied by a review of provincial and municipal and centrespecific regulations. Finally, the purpose of planning time must not be solely used for other tasks and for the production of documentation. I argue in order to activate a transforming society approach to early childhood education, educators must have time to think, question, read, discuss, theorize as well as plan and document, not only children's learning, but also the dominant discourses that pervade early childhood. It is likely that calling this contested time 
"planning time" may ultimately be inadequate and may need to be called something else altogether.

My recommendations for early childhood educators reading this is to continue to resist. This research study is intended to be a site of activism (Cannella, 2018; Wolff, 2013) that I hope will incite early childhood educators to take even greater ethical and political stands. As predominately women, educators have collective power to resist and change the systems that oppress them. Osgood (2006) encourages educators to take up this "challenge and appl[y]/[develop] Foucauldian concepts to create counter-discourses to destabilise established/dominant constructions and confuse, or open space for alternative identity constructions, leading to enhanced self-esteem and individual empowerment" (p. 10). Osgood (2006) and others (Cannella,1997, 2018; Dahlberg, Moss and Pence, 2006; Langford, 2010; MacNaughton, 2003, 2005; Moss, 2019) encourage educators to engage in critical reflection and reflexivity of their own self as a subject as well as the dominant discourses that shape their practice and identity as professionals.

\section{Conclusion}

In this study I have addressed the issue of a lack of paid planning time for early childhood educators. The purpose of this study was to lift the voices of educators about this overlooked issue as their voices are lacking in much research that informs policy directly affecting them. To this end, I used a critical qualitative inquiry approach to engage with marginalized voices. I exposed the power structures of neoliberalism and discourses of developmentalism and that good educators that shape and oppress mostly female educators by using feminist poststructural and queer time as theoretical frameworks. In providing a feminist and reconceptualist reading of the findings woven into the discussion, I attempted to deconstruct 
neoliberal and developmental discourses and to establish this research study as a site for activism.

The findings indicate that educators indeed need paid planning time in order to meet the expectations imposed on them. The findings reveal specifically that educators need daily, ample planning time. They need to have autonomy and flexibility in their use of planning time, and they need to have planning time together with their teaching partners. Educators also called for a revision of the regulations and for quotas documentation, especially at a centre management level, and to be included in decisions about regulations. The findings further reveal that educators are resisting regulations and expectations within neoliberal and developmental systems and discourses and points to How Does Learning Happen? as a tool of resistance. Finally, it is clear that early childhood educators value paid planning time as contributing positively to their wages and working conditions, as well as their work as professionals.

I contend in this study that planning time is dangerous. A lack of paid planning time is dangerous as it lowers educators' wages, contributes to their poor working conditions, and causes stress. It is dangerous because it is a regulated time, ordered around production in a world that values production, consumption and profits over living well with others and with our planet. It is also dangerous because of its potential for questioning and challenging the status quo in an effort to transform early childhood education. I argue that educators have a critical role to play in transforming programs into more democratic and livable spaces and that in order to accomplish this they require time to think, read, question, discuss, theorize, plan and document together. How Does Learning Happen? stands on the edge of the dominant discourses that are currently at work in early childhood education as a tool of resistance to assist early childhood educators in seeing their work as ethical and political and for questioning and challenging the status quo 


\section{APPENDICES}

\section{APPENDIX A: Interview Guide}

Preamble:

Welcome to this focus group session. The purpose of this study is to seek your perspective as an RECE on your experiences with paid and/or unpaid planning time. I want to thank you for attending and sharing your perspectives. I want to remind you that your participation in this study is completely voluntary and you may withdraw at any time. A decision to withdraw will not affect any further relations that you may have with Ryerson University, Dr, Rachel Langford and the School of Early Childhood Studies, the Ryerson University Research Ethics Board or the principal investigator Lisa Johnston.

I also want to remind you that this session will be audio recorded. The purpose of audio recording the session is so that the session may be later transcribed and then analyzed as part of this study. Remember that you are under no obligation to participate and you may choose to withdraw from the study at any time without any consequence. Please note however, that due to the nature of focus group discussions, it may not be feasible to remove any data that you may have already contributed. If you do not wish to be audio recorded, you may leave the session now. (Pause) If you still wish to participate, but do not want to be audio recorded, you will have the opportunity to answer the questions on paper or schedule a one on one interview. All names of participants will be changed to pseudonyms during the transcribing of the data. To help with keeping track of who is speaking during the focus group discussion, please say your name or initials each time before you speak. Also, please only refer to your place of employment as "my centre" and not by its actual name to ensure confidentiality. Be advised that no places of employment will be identified by names in the study. It is possible that some of you may know 
me or each other. I will remind you that when you signed your consent form that you also signed to agree to maintain the confidentiality of the other participants and their/your employers. This means that you will not disclose any information shared during this focus group session with any third party outside of this focus group session. I also ask that you refrain from speaking negatively of your employer and remember that wages and working conditions for ECEs are a broader systemic issue that is often beyond the control of the employer.

I will be personally transcribing the audio recording. The only other person that will have access to the audio recordings will be my research supervisor Dr. Rachel Langford. Her contact information is on your information letter and your copy of the consent form. I ask that you respect the confidentially of the other participants and that you do not share any information spoken here outside of this focus group session. I want to remind you that although we have agreed to maintain the confidentiality of the participants, I cannot guarantee that confidentiality will be maintained by everyone outside the focus group session. Any information shared during this focus group session will only be used for the purpose of this study.

I must also remind you that if at any point during the focus group, I am notified of an instance of or I suspect any child abuse or neglect concerning the welfare of a child, I will be required to terminate the focus group session. As I am also a registered Early Childhood Educator, I am bound by a 'Duty to Report' clause in the Child, Youth and Family Services Act, 2017 in accordance with the Code of Ethics and Standards of Practice by the College of Early Childhood Educators Ontario and in this case those participants will forfeit their right to confidentiality.

I will be asking a series of questions. We will start by going around the circle and answering. You may skip any question that you do not feel comfortable answering. You may 
also ask your own questions and respond to each other as you feel inclined. Are there any questions about anything before we begin?

Warm up questions:

1. How long have you worked as an RECE?

2. Do you have paid or unpaid planning time?

Reconstructing questions:

1. Please describe when, where and how you do your program planning?

2. What actually happens during your planning time?

Reflecting questions:

1. Why do you/don't you have planning time?

2. Who is responsible for you having or not having planning time?

3. What does paid or unpaid planning time mean to you?

4. In How Does Learning Happen?, ECEs are referred to as researchers, engaged in critical reflection and collaborative inquiry. How does this relate to your experience?

5. The AECEO has made policy recommendations for all ECEs to have paid planning time. What needs to happen to make this a reality?

6. In your dream scenario, how would you use your paid planning time?

7. How is planning time political and ethical?

8. Quote to think with:

Possible probing questions:

9. How does having paid or unpaid planning time impact on your time with children?

10. How does having paid or unpaid planning impact your general working conditions?

11. Which documents do you refer to in order to guide your program planning? 
12. What other demands are there on your time?

Debrief:

- Read over some of the main points in the notes taken and ask of there are any other comments or questions to add or clarify.

Thank you for your participation. The final report will be out by the end of August. I plan to disseminate the results of the study in the form of a research brief and a formal research study article. These will be sent out through the AECEO mailing list as well as a link to the MRP Repository at Ryerson University. If you would like to review the results prior to publication of the study please send an email to the principal investigator Lisa Johnston at lisa.johnston@ryerson.ca. Also, if you would like to continue the conversation about planning time, how to make it happen and your role as a co-researcher with children send an email to lisa.johnston@ryerson.ca. 


\section{APPENDIX B: RECRUITMENT FLYER}

\section{RESEARCH PARTICIPANTS NEEDED}

Dangerous time: A critical qualitative inquiry into Ontario ECEs' perspectives on planning time.

Are You:

- A Registered ECE or childcare worker?

- Working full time or part time in Ontario in a licensed childcare centre or Full Day Kindergarten program?

- Working or have worked for at least 2 years?

- Do you have paid or unpaid planning time?

If you answered yes to all of the above, you are eligible to participate in this study. The study is looking to better understand ECEs' perspectives on planning time, whether paid or unpaid. What are ECEs experiences with planning time? What do ECE's need to ensure that their planning time is useful for their ability to critically reflect and engage in collaborative inquiry?

Your participation will involve attending one focus group session at Ryerson University. The focus group will be 60-90 minutes in length. The focus group will take place on Ryerson campus on June 19 at 6:30 at 99 Gerrard Street East in room 698. In appreciation of your time, refreshments will be provided at the focus group session and you will be reimbursed for your travel costs up to $\$ 7.50$ (TTC fare or parking in Victoria St. parking garage). Participating in a research study may also contribute to your Continuous Professional Learning.

Funding for this study has been approved and generously provided by the Ryerson University School of Early Childhood Studies.

Participation in this study is completely voluntary. You can choose whether to be in this study or not. If any question makes you uncomfortable, you can skip that question. You may stop participating at any time. Your choice of whether or not to participate will not influence your future relations with the AECEO, Ryerson University, Dr, Rachel Langford, or the investigator, Lisa Johnston.

If you are interested in participating in this study, or would like more information, please contact: Lisa Johnston at lisa.johnston@ @yerson.ca. Please respond as soon as possible to receive information about date, time and location.

I am a graduate student in the School of Early Childhood Studies at Ryerson University and this study is part of the requirements for the completion of my Master of Arts in Early Childhood Studies degree under the supervision of Dr. Rachel Langford at the School of Early Childhood Studies, 416-979-5000 x2516, rlangfor@ ryerson.ca. The primary researcher of this study is Lisa Johnston. This research study has been reviewed and approved by the Ryerson University Research Ethics Board. REB protocol number 2019-095. 


\section{APPENDIX C: CONSENT FORM}

\section{Ryerson University \\ Consent Agreement}

You are being invited to participate in a research study. Please read this consent form so that you understand what your participation will involve. Before you consent to participate, please ask any questions to be sure you understand what your participation will involve.

\section{TITLE OF THE STUDY}

Dangerous time: A critical qualitative inquiry into Ontario ECEs' perspectives on planning time.

\section{INVESTIGATORS}

This research study is being conducted by Lisa Johnston, a graduate student in the Master of Arts in Early Childhood Studies program in the School of Early Childhood Studies at Ryerson University, and under the supervision of Dr. Rachel Langford, Associate Professor in the School of Early Childhood Studies at Ryerson University.

If you have any questions or concerns about the research, please feel free to contact Lisa Johnston at lisa.johnston@ ryerson.ca

\section{PURPOSE OF THE STUDY}

The purpose of this study is to better understand Ontario Early Childhood Educators' perspectives on and experiences with planning time. As planning curriculum is a central aspect of an ECE's role, it is important to hear directly from ECEs on this topic. This study will contribute to a dearth of qualitative studies that focus on planning time for ECEs. A total of 12 participants will be recruited to participate in a focus group session. Participants must be a Registered Early Childhood Educator or child care worker currently working or has recently worked in a full time or part time position in a licensed childcare or full day kindergarten program in Ontario. They must have been working for at least 2 years or more. Potential participants who are not Registered Early Childhood Educators or childcare workers, who are not working in a licensed childcare centre or full day kindergarten program in Ontario, for at least two years will not be eligible to participate in this study. This research is being conducted by a graduate student in partial completion of a degree requirement and the results will contribute to a major research paper.

\section{WHAT YOU WILL BE ASKED TO DO}

If you volunteer to participate in this study, you will be asked to do the following things:

Attend one 60 - 90 minute focus group session on Ryerson campus where you will be asked to respond to questions about your perspectives on and experiences with planning time. Sample focus group questions may be:

- Describe how and when you plan your curriculum?

- Who is responsible for you having or not having planning time?

- What does paid or unpaid planning time mean to you? 
- In How Does Learning Happen?, ECEs are referred to as researchers, engaged in critical reflection and collaborative inquiry? How does this relate to your experience?

- The AECEO has made policy recommendations for all ECEs to have paid planning time. What needs to happen to make this a reality?

- What actually happens during your planning time?

- Ideally, how would you use your planning time?

Prior to publication, the findings of the study will be shared with participants for review. Participants will have a one-week window in which to provide feedback or comments. Findings from the study will be complied in a research brief and shared through the Association of Early Childhood Educators Ontario member email list and also on their Facebook page. Participants may also request a copy of the research report directly from the investigator. Furthermore participants may access the final research paper on the Ryerson Digital Repository where all MRPs are uploaded upon completion by following this link https://digital.library.ryerson.ca/.

\section{POTENTIAL BENEFITS}

I cannot guarantee that you will receive any benefits from participating in this study.

It is hoped that the information gathered may be useful for informing stakeholders and decision makers about the importance of providing paid planning time for ECEs.

\section{WHAT ARE THE POTENTIAL RISKS TO YOU AS A PARTICIPANT?}

Potential risks to you as a participant are very low. However, potential risks may include psychological risk, social risk and/or personal identity being revealed.

Psychological Risk: The psychological risk to you is minimal. You may feel anxious or uncomfortable speaking in a group or speaking about the particular topic. You may also feel uncomfortable being audio recorded. To minimize this risk efforts will be made to conduct the focus group in a relaxed, conversational style to help put you at ease. You will be reminded that your participation is voluntary and that you do not have to answer any questions that you are not comfortable with. If, at any point during the focus group session you begin to feel uncomfortable, you may skip answering a question or stop participation, either temporarily or permanently.

Social Risk: The social risk to you is minimal. It is possible that you may feel embarrassed in discussions with other participants. This is particularly the case when speaking in a focus group in front of other people. It is also possible that you may worry about a potential loss of privacy when you share their thoughts and ideas. To minimize feelings of embarrassment, the focus group environment will be relaxed and informal. You will be assured ahead of each focus group that you are invited to share their thoughts, ideas, feelings, and perspectives, and that there are no right or wrong answers. You will also be given the option of sharing your perspective on a oneto-one basis as an alternative to the focus group setting. At the beginning of the focus group, you will be reminded that you can choose which questions to answer and that any identifying names will be changed to pseudonyms.

Risk of Personal Identity being Revealed: The risk of your personal identity being revealed is minimal. You may discover that you know one or more participants in the focus group, or you may know the investigator. To minimize this risk, you will be assured and informed that the 
investigator and the research supervisor will maintain the confidentiality of the participants. You will also be asked to respect and maintain the confidentiality of the other participants in the focus group. The investigator will inform you and the other participants that while all participants are asked to maintain the confidentiality of other participants, the investigator cannot guarantee that all participants will honour this request. You will be reminded that you have the right to withdraw from the study at any time without consequence. Another potential risk to personal identity being revealed is that the focus group will be audio recorded. To minimize this risk, you will be assured and informed that the audio recording will only be available to the investigator and the research supervisor. As well, transcription of the audio recording will be done by the investigator only and will not be done by an outside source. You will also be assured and reminded that pseudonyms will be used to maintain your confidentiality and no other identifying information will be included in the transcripts. Finally, if you feel uncomfortable at any time you will be reminded that you have the option to withdraw from the study or from the focus group. If you choose to withdraw from the focus group, you still have the option to participate by means of a one on one interview or by providing written responses to the questions.

\section{CONFIDENTIALITY}

Measures will be taken to ensure your information is kept confidential. All identifying names will be changed to pseudonyms. The audio recordings and research data will only be available to the investigator and the research supervisor. The focus group session will be conducted on Ryerson campus in a classroom where the door can be closed, and windows can be covered to ensure aural and visual privacy of all participants. You will be asked to keep the identity of the other participants and the information shared private. Data gathered from the focus group session will be kept for one year. All identifying information (names and email addresses and consent forms) will be stored separately in a locked cabinet in the research supervisor's locked office in the School of Early Childhood Studies at Ryerson University. Audio recordings gathered from the focus group session and transcriptions will be stored on a Google Drive accessible only by a password encrypted Ryerson email. Only the investigator and the research supervisor will have access to the audio recording and the transcript. One year after the completion of the study, all data stored electronically will be deleted and all hard copies of information will be destroyed by shredding.

\section{DUTY TO REPORT}

Please note that if at any point during the focus group, the researcher is notified of an instance of or suspects any child abuse or neglect concerning the welfare of a child, the researcher will be required to terminate the focus group session. As the researcher is also a Registered Early Childhood Educator, the researcher is bound by a 'Duty to Report' clause in the Child, Youth and Family Services Act, 2017 in accordance with the Code of Ethics and Standards of Practice by the College of Early Childhood Educators Ontario and in this case those participants will forfeit their right to confidentiality.

\section{INCENTIVES FOR PARTICIPATION}

Refreshments will be provided at the focus group session. You will be reimbursed for your travel costs up to $\$ 7.50$. This will cover either a two-way TTC fare a one-time evening parking fee in the Victoria Street parking garage. 


\section{COSTS OF PARTICIPATION}

There is no cost to you for participating in the study. Your travel costs will be reimbursed up to $\$ 7.50$. This will cover the cost a two-way TTC cash fare or a one-time evening (after $6 \mathrm{pm}$ ) parking fee in the Victoria street parking garage.

\section{FUNDING}

Funding for the provision of travel reimbursements and refreshments have been approved and generously provided by the Ryerson University School of Early Childhood Studies.

\section{VOLUNTARY PARTICIPATION AND WITHDRAWAL}

Participation in this study is completely voluntary. You can choose whether to be in this study or not. If any question makes you uncomfortable, you can skip that question. You may stop participating at any time. If you choose to withdraw from the study, please note that due to the nature of focus group discussions it may not be feasible to remove any data you may have already contributed. Your choice of whether or not to participate will not influence your future relations with the AECEO, Ryerson University, Dr. Rachel Langford and the School of Early Childhood Studies or the investigator, Lisa Johnston.

\section{QUESTIONS ABOUT THE STUDY}

If you have any questions about the research now, please ask. If you have questions later about the research, you may contact: Lisa Johnston via email at lisa.johnston@ryerson.ca

This study has been reviewed by the Ryerson University Research Ethics Board.

REB Approval \#2019-095

If you have questions regarding your rights as a participant in this study, please contact:

Research Ethics Board

c/o Office of the Vice President, Research and Innovation

Ryerson University

350 Victoria Street

Toronto, ON M5B 2K3

416-979-5042

rebchair@ryerson.ca

Dangerous time: A critical qualitative inquiry into Ontario ECEs' perspectives on planning time.

\section{CONFIRMATION OF AGREEMENT}

In order to participate in this study, you must provide your voluntary, informed consent to participate. By signing the consent form, you are not waiving any legal rights in the event of research-related harm. Your signature below indicates that you have read the information in this agreement and have had a chance to ask any questions you have about the study. Your signature also indicates that you agree to participate in the study and have been told that you can change your mind and withdraw your consent to participate at any time. You have been given a copy of this agreement. You have been told that by signing this consent agreement you are not giving up any of your legal rights. 
Name of Participant (please print)

Signature of Participant Date

I agree to be audio recorded for the purposes of this study. I understand how these recordings will be stored and destroyed.

$\overline{\text { Signature of Participant }} \overline{\text { Date }}$

I agree to maintain the confidentiality of all participants and their employers in the focus group by not disclosing any information shared during the focus group to any third party or others outside that focus group.

Signature of Participant

Date 


\section{REFERENCES}

Adam, B. (1994). Beyond boundaries: Reconceptualizing time in the face of global challenges. Social Science Information, 33(4), 597-620.

doi:10.1177/053901894033004003

Adam, B. (2006). time. Theory, Culture \& Society, 23(2-3), 119-126.

doi:10.1177/0263276406063779

Association of Early Childhood Educators Ontario (2016a). How does learning happen?

Inspirational pedagogy in everyday practice depends on a well-supported ECE workforce. eceLink Summer 2016, 6-9. Toronto, ON: AECEO. Retrieved from: https://d3n8a8pro7vhmx.cloudfront.net/aeceo/pages/916/attachments/original/146774794 7/HowDoesLearningHappen_eceLINKSum16.pdf?1467747947

Association of Early Childhood Educators Ontario (2016b). "I'm more than 'just' an ECE": Decent work from the perspective of Ontario's early childhood workforce. eceLink Fall 2016, 6-11. Toronto, ON: AECEO. Retrieved from: https://d3n8a8pro7vhmx.cloudfront.net/aeceo/pages/941/attachments/original/147673592 4/Im_more_than_just_an_ece.pdf?1476735924

Association of Early Childhood Educators Ontario, Decent Work Task Force (2017). Transforming work in Ontario's early years and childcare sector. Workforce strategy recommendations presented to the Ministry of Education. Retrieved from: https://d3n8a8pro7vhmx.cloudfront.net/aeceo/pages/2268/attachments/original/15120105 36/AECEO_Recommendations_FinalReport_2017.pdf?1512010536

Association of Early Childhood Educators Ontario, (n.d.). Professional pay and decent work campaign. Retrieved from: https://www.aeceo.ca/professional_pay_decent_work_for_all 
Atkinson Centre (2017). The Early Childhood Education Report. Retrieved from: http://ecereport.ca/media/uploads/2017-report-pdfs/ece-report2017-en-feb6.pdf

Bernhard, J. (2002). Toward a 21st century developmental theory: Principles to account for diversity in children's lives. Race, Gender \& Class, 9(4), 45-45.

Best Start Expert Panel on Early Learning. (2007). Early learning for every child today: A framework for Ontario early childhood settings. Toronto: Ministry of Children and Youth Services. Retrieved from: http://www.edu.gov.on.ca/childcare/oelf/continuum/continuum.pdf

Bloch, M., Swadener, B., \& Cannella, G. (2014). Introduction: Exploring reconceptualist histories and possibilities. In M.N. Bloch, B.B. Swadener, \& G. Cannella (Eds.), Reconceptualizing early childhood care and education: critical questions, new imaginaries and social activism (pp. 1-16). New York: Peter Lang.

Bloch, M., Swadener, B. \& Cannella, G. (2018). Reconceptualizing early childhood care an education: A reader: Critical questions, new imaginaries and social activism. Second Edition, New York, NY: Peter Lang.

Blöchliger, O. R., \& Bauer, G. F. (2018). Correlates of burnout symptoms among childcare teachers. A multilevel modeling approach. European Early Childhood Education Research Journal, 26(1), 7-25. doi:10.1080/1350293X.2018.1412012

Bredekamp, S., \& Copple, C. (1997). Developmentally appropriate practice in early childhood programs (Rev. ed.). Washington, DC: National Association for the Education of Young Children.

Boyd, M. (2013). "I love my work but..." the professionalization of early childhood 
education. The Qualitative Report, 18(36), 1-20. Retrieved from

http://ezproxy.lib.ryerson.ca/login?url=https://search-proquest-

com.ezproxy.lib.ryerson.ca/docview/1505321572?accountid=13631

Burman, E. (1994). Deconstructing developmental psychology. Routledge.

Cannella, G. S. (1997). Deconstructing early childhood education: Social justice and revolution Peter Lang.

Cannella, G.S. (2018). Critical qualitative research and rethinking academic activism in childhood studies. In M. Bloch, B Swadener, \& G. Cannella, (Eds.). Reconceptualizing early childhood care and education: A reader: Critical questions, new imaginaries and social activism. (pp.337-348). Second Edition, New York, NY: Peter Lang.

Cannella, G. S., Pérez, M. S., \& Pasque, P. A. (2016). Critical qualitative inquiry: Foundations and futures Left Coast Press.

Centres of Excellence for Early Years and Child Care. (2019). About us: What is the role of a Pedagogist? Retrieved from: https://ceeycc-cepege.ca/provincial-en/about-us/

City of Toronto, (2019). Assessment for Quality Improvement (AQI) Retrieved from: https://www.toronto.ca/community-people/community-partners/early-learning-child-carepartners/assessment-for-quality-improvement-aqi/

Child Care Sector Human Resources Council. (2013). "You bet we still care!" A survey of centre-based early childhood education and care in Canada, p. 8. Highlights report. Retrieved from: http://www.ccsc-cssge.ca/sites/default/files/uploads/Projects-PubsDocs/EN\%20Pub\%20 Chart/YouBetSurveyReport_Final.pdf.

College of Early Childhood Educators (2019). Purpose and mandate. Retrieved from: https://www.college-ece.ca/en/About-Us/Purpose-and-Mandate 
Creswell, J.W. (2014). Research design: qualitative, quantitative and mixed methods approaches. Sage Publications

Curbow, B., Spratt, K., Ungaretti, A., McDonnell, K., \& Breckler, S. (2000). Development of the childcare worker job stress inventory. Early Childhood Research Quarterly, 15(4), 515536. doi:10.1016/S0885-2006(01)00068-0

Dahlberg, G. \& Moss, P. (2005). Ethics and politics in early childhood education. London: Routledge Falmer.

Dahlberg, G. \& Moss, P. (2018). Reconceptualising Evaluation in Early Childhood Education. In M. Bloch, B Swadener, \& G. Cannella, (Eds.). Reconceptualizing early childhood care and education: A reader: Critical questions, new imaginaries and social activism. (pp. 92-111). Second Edition, New York, NY: Peter Lang.

Dahlberg, G., Moss, P., \& Pence, A. R. (2006). Beyond quality in early childhood education and care: Languages of evaluation (2nd ed.) Routledge.

Davies, B. \& Bansel, P. (2007) Neoliberalism and Education. International Journal of Qualitative Studies in Education. 20(3). 247- 259, doi:10.1080/09518390701281751

Deleuze, G., Guattari, F., \& Massumi, B. (1987). A thousand plateaus: Capitalism and Schizophrenia. University of Minnesota Press.

Denzin, N. K. (2017). Critical qualitative inquiry. Qualitative Inquiry, 23(1), 8-16. doi:10.1177/1077800416681864

Doherty, G., Lero, D., Goelman, H., LaGrange, A. \& Tougas, J. (2000). You bet I care. A Canada-wide study on wages, working conditions and practices in child care centres, pp. 69-84. Guelph: Centre for Families Work and Well-Being, University of Guelph, Ontario. 
Edwards, C. P., Gandini, L., \& Forman, G. E. (2012). The hundred languages of children: The Reggio Emilia experience in transformation (3rd ed.) Praeger.

Escayg, K-A, Berman, R. \& Royer, N. (2017). Canadian children and race: Toward an antiracism analysis. Journal of Childhood Studies, 42(2). 10-21.

Farquhar, S., \& Tesar, M. (2016). Focus groups as temporal ecosystems for newly qualified early childhood teachers. Contemporary Issues in Early Childhood, 17(3), 261-274. doi:10.1177/1463949116660949

Faulkner, M., Gerstenblatt, P., Lee, A., Vallejo, V., \& Travis, D. (2016). Childcare providers: Work stress and personal well-being. Journal of Early Childhood Research, 14(3), 280 293. https://doi.org/10.1177/1476718X14552871

Foucault, M. (1979). Discipline and punish: The birth of the prison. Vintage Books.

Foucault, M. (1978). The History of Sexuality: Volumes I-III. New York: Pantheon.

Foucault, M. (1980). In C. Gordon (Ed.), Power/knowledge: Selected interviews and other writings, 1972-1977. Brighton: Harvester.

Foucault, M. (1983) 'On the genealogy of ethics: an overview of work in progress', in H.L. Dreyfus an P. Rabinow (eds). Michel Foucault: Beyond Structuralism and Hermeneutics (2nd edition) with an Afterward by and an Interview with Michel Foucault, Chicago: The University of Chicago Press.

Halberstam, J. (2005). In a queer time and place: Transgender bodies, subcultural lives. New York University Press.

Halfon, S. \& Langford, R. (2015). Developing and supporting a high quality child care 
workforce in Canada: What are the barriers to change? Retrieved from:

https://www.policyalternatives.ca/sites/default/files/uploads/publications/National\%20Of fice/2015/09/OS120_Sumer2015_Workforce.pdf

Haraway, D. (2016). Staying with the trouble. Making kin in the chthulucene. Duke University Press.

Hatch, J. A. \& Coleman-King, C. (2015). Conducting early childhood qualitative research in the twenty-first century. In O. N. Saracho, (Ed.), Handbook of research methods in early childhood education. volume 1, review of research methodologies Information Age Publishing, Inc. (pp. 441-478)

Holochwost, S. J., DeMott, K., Buell, M., Yannetta, K., and Amsden, D. (2009). Retention of staff in the early childhood education workforce. Child \& Youth Care Forum, 38(5), 227237. doi:10.1007/s10566-009-9078-6

Iorio, J.M., Parnell, W., Quintero, E.P. \& Hamm. C., (2018). Early childhood teacher educator as public intellectual. In M. Bloch, B Swadener, \& G. Cannella, (Eds.). Reconceptualizing early childhood care and education: A reader: Critical questions, new imaginaries and social activism. (pp.299-312). Second Edition, New York, NY: Peter Lang.

Janmohamed, Z., McCuaig, K., Akbari, E., Gananathan, R., \& Jenkins, J. (2014). Schools at the Centre: Findings from Case Studies Exploring Seamless Early Learning in Ontario. Toronto, ON: Atkinson Centre for Society and Child Development, OISE/University of Toronto.

Kipnis, F., Whitebook, M., Almaraz, M., Sakai, L., \& Austin, L. J. E. (2012). Learning together: 
A study of six B.A. completion cohort programs in early care and education. Year 4.

Berkeley, CA: Center for the Study of Child Care Employment, University of California, Berkeley.

Kitzinger, J. (1994). The methodology of focus groups: The importance of interaction between research participants. Sociology of Health and Illness, 16(1), 103-121. doi:10.1111/14679566.ep11347023

Kummen, K. (2010) Is it Time to Put 'Tidy up Time' Away? Contesting Routines and Transitions in Early Childhood Spaces, in V. Pacini-Ketchabaw (Ed.) Flows, Rhythms, and Intensities of Early Childhood Education Curriculum, pp. 97-112. New York: Peter Lang.

Langford, R. (2007). Who is a good early childhood educator? A critical study of differences within a universal professional identity in early childhood education preparation programs. Journal of Early Childhood Teacher Education, 28(4), 333-352. doi:10.1080/10901020701686609

Langford, R. (2010). Critiquing Child-Centred Pedagogy to Bring Children and Early Childhood Educators into the Centre of a Democratic Pedagogy. Contemporary Issues in Early Childhood, 11(1), 113-127 http://dx.doi.org/10.2304/ciec.2010.11.1.113

Langford, R., Richardson, B., Albanese, P., Bezanson, K., Prentice, S., \& White, J. (2017). Caring about care: Reasserting care as integral to early childhood education and care practice, politics and policies in Canada. Global Studies of Childhood, 7(4), 311-322. doi: $10.1177 / 2043610617747978$

Leavy, P. (2017). Research design: quantitative, qualitative, mixed methods, arts-based, and community based participatory approaches. Guilford Press 
MacNaughton, G. (2003). Shaping early childhood: Learners, curriculum and contexts. Open University Press.

MacNaughton, G. (2005). Doing Foucault in early childhood studies: Applying poststructural ideas. Routledge.

Moss, P. (2006). Structures, understandings and discourses: Possibilities for re-envisioning the early childhood worker. Contemporary Issues in Early Childhood, 7(1), 30-41. doi:10.2304/ciec.2006.7.1.30

Moss, P. (2010). We cannot continue as we are: the educator in an education for survival. Contemporary Issues in Early Childhood, 11(1), 8-19.

Moss, P. (2015). There are alternatives! contestation and hope in early childhood education. Global Studies of Childhood, 5(3), 226-238. doi:10.1177/2043610615597130

Moss, P. (2019). Alternative narratives in early childhood: An introduction for students and practitioners Routledge, an imprint of the Taylor \& Francis Group.

Mukherji, P., and Albon, D. (2010). Research methods in early childhood: An introductory guide. Sage Publications

Neuman, W. L., \& Robson, K. (2012). Basics of social research: Qualitative and quantitative approaches (2nd Canadian ed.) Pearson, Allyn and Bacon.

OECD (2006). Starting Strong II: Early Childhood Education and Care, Starting Strong, OECD Publishing, Paris, https://doi.org/10.1787/9789264035461-en

OECD (2015). Starting Strong IV: Monitoring Quality in Early Childhood Education and Care, OECD Publishing, Paris. DOI: http://dx.doi.org/10.1787/9789264233515-en

OECD (2017). Starting Strong 2017: OECD Indicators on Early Childhood Education and Care, OECD Publishing, Paris. DOI: http://dx.doi.org/10.1787/9789264276116-en 
Ontario Ministry of Education. (2014a). Child Care Early Years Act. Toronto: Author.

Retrieved from:

https://www.ontario.ca/laws/statute/14c11? ga=1.118789642.285872937.1462810424

Ontario Ministry of Education. (2014b). Excerpts from ELECT. Toronto: Author. Retrieved from: http://www.edu.gov.on.ca/childcare/ExcerptsFromELECT.pdf

Ontario Ministry of Education. (2014c). How does learning happen? Ontario's pedagogy for the early years: A resource about learning through relationships for those who work with young children and their families. Toronto: Author. Retrieved from: http://www.edu.gov.on.ca/childcare/HowLearningHappens.pdf

Osgood, J. (2006). Deconstructing professionalism in early childhood education: Resisting the regulatory gaze. Contemporary Issues in Early Childhood, 7(1), 5-14. doi:10.2304/ciec.2006.7.1.5

Pacini-Ketchabaw, V. (2012) Acting with the clock: Clocking practices in early childhood. Contemporary Issues in Early Childhood 13(2): 154-160.

Pacini-Ketchabaw, V. \& Kummen, K. (2016). Shifting temporal frames in children's common worlds in the anthropocene. Contemporary Issues in Early Childhood, 17(4), 431-441. doi:10.1177/1463949116677930

Pacini-Ketchabaw, V., Nxumalo, F., Kocher, L., Elliott, E., \& Sanchez, A. (2015). Journeys: Reconceptualizing early childhood practices through pedagogical narration. University of Toronto Press.

Phillips, D., Lea J. E. Austin, \& Whitebook, M. (2016). The early care and education workforce. The Future of Children, 26(2), 139-158. doi:10.1353/foc.2016.0016

Richardson, L., \& St. Pierre, E. A. (2005). Writing: A method of inquiry. In N. K. Denzin \& Y. 
S. Lincoln (Eds.), The SAGE handbook of qualitative research (pp. 959-978). Thousand Oaks, CA: Sage.

Roberts, A. M., Gallagher, K. C., Daro, A. M., Iruka, I. U., \& Sarver, S. L. (2017). Workforce well-being: Personal and workplace contributions to early educators' depression across settings. Journal of Applied Developmental Psychology

doi:10.1016/j.appdev.2017.09.007

Rose, S. \& Whitty, P. (2010) 'Where Do We Find the Time to Do This?' Struggling against the Tyranny of Time, Alberta Journal of Educational Research, 56(3), 257-273.

Ryan, S. \& Goffin, S. G. (2008). Missing in action: Teaching in early care and education. Early Education \& Development, 19(3), 385-395. doi:10.1080/10409280802068688

Seidman, I. (2013). Interviewing as qualitative research: A guide for researchers in education and the social sciences (4th ed.) Teachers College Press

Silin, J. (2018). Through a queer lens: Recuperative longings and the reconceptualizing past. In M. Bloch, B Swadener, \& G. Cannella, (Eds.). Reconceptualizing early childhood care and education: A reader: Critical questions, new imaginaries and social activism. (pp. 56-66). Second Edition, New York, NY: Peter Lang.

Smith, K. \& Campbell, S., (2018). Social activism: The risky business of early childhood educators in neoliberal Australian classrooms. In M. Bloch, B Swadener, \& G. Cannella, (Eds.). Reconceptualizing early childhood care and education: A reader: Critical questions, new imaginaries and social activism. (pp. 313-324). Second Edition, New York, NY: Peter Lang.

St. Pierre, E. A. (2000). Poststructural feminism in education: An overview. International 
Journal of Qualitative Studies in Education, 13(5), 477-515.

doi:10.1080/09518390050156422

Taylor, A. (2018). Situated and entangled childhoods: Imagining and materializing children's common world relations. In M. Bloch, B Swadener, \& G. Cannella, (Eds.). Reconceptualizing early childhood care and education: A reader: Critical questions, new imaginaries and social activism. (pp. 205-214). Second Edition, New York, NY: Peter Lang.

Totenhagen, C. J., Hawkins, S. A., Casper, D. M., Bosch, L. A., Hawkey, K. R., \& Borden, L. M. (2016). Retaining early childhood education workers: A review of the empirical literature. Journal of Research in Childhood Education, 30(4), 585-599. doi:10.1080/02568543.2016.1214652

Tronto, J. (2003). Time's place. Feminist Theory, 4(2), 119-138. doi: $10.1177 / 14647001030042002$

Underwood, K., Santo, A. D., Valeo, A., \& Langford, R. (2016). Partnerships in full-day kindergarten classrooms: Early childhood educators and kindergarten teachers working together. Canadian Children, 41(1), 36-45.

doi:http://dx.doi.org.ezproxy.lib.ryerson.ca/10.18357/jcs.v41i1.15696

Urban, M., Vandenbroeck, M., Laere, K. V., Lazzari, A., \& Peeters, J. (2012). Towards competent systems in early childhood education and care. implications for policy and practice. European Journal of Education, 47(4), 508-526. doi:10.1111/ejed.12010

Vintimilla, C. D. (2018). Encounters with a pedagogista. Contemporary Issues in Early Childhood, 19(1), 20-30. doi:10.1177/1463949116684886

Wagner, S., Forer, B., Cepeda, I., Goelman, H., Maggi, S., D’Angiulli, A., Grunau, R. (2013). 
Perceived stress and Canadian early childcare educators. Child \& Youth Care Forum, 42(1), 53-70. doi:10.1007/s10566-012-9187-5

Walkerdine, V. (1988). The mastery of reason: Cognitive development and the production of rationality. London: Routledge.

Whitebook, M., \& Ryan, S. (2011). Degrees in context: Asking the right questions about preparing skilled and effective teachers of young children. Rutgers, NJ: National Institute for Early Education Research. Retrieved from: http://nieer.org/wpcontent/uploads/2016/08/23-2.pdf

Wien, C.A. (1996). Time, Work, and Developmentally Appropriate Practice, Early Childhood Research Quarterly, 11, 377-403. http://dx.doi.org/10.1016/S0885-2006(96)90013-7

Wien, C.A., \& Kirby-Smith, S. (1998). Untiming the curriculum: A case study of removing clocks from the program. Young Children, 53(5): 8-13.

Wolff, K. (2013). When more is not more: Consumption and consumerism within the neoliberal early childhood assemblage(s). Global Studies of Childhood, 3(3), 328-338. doi:10.2304/gsch.2013.3.3.328 
